\title{
Comprehensive analysis of drugs to treat SARS-CoV-2 infection: Mechanistic insights into current COVID-19 therapies (Review)
}

\author{
GEORGE MIHAI NITULESCU ${ }^{1}$, HORIA PAUNESCU ${ }^{2}$, STERGHIOS A. MOSCHOS $^{3,4}$, \\ DIMITRIOS PETRAKIS ${ }^{5}$, GEORGIANA NITULESCU ${ }^{1}$, GEORGE NICOLAE DANIEL ION ${ }^{1}$, \\ DEMETRIOS A. SPANDIDOS ${ }^{6}$, TAXIARCHIS KONSTANTINOS NIKOLOUZAKIS ${ }^{5}$, \\ NIKOLAOS DRAKOULIS ${ }^{7}$ and ARISTIDIS TSATSAKIS ${ }^{5}$
}

\author{
${ }^{1}$ Faculty of Pharmacy, ${ }^{2}$ Faculty of Medicine, 'Carol Davila' University of Medicine and Pharmacy, 020956 Bucharest, \\ Romania; ${ }^{3}$ Department of Applied Sciences, Faculty of Health and Life Sciences, Northumbria University; \\ ${ }^{4}$ PulmoBioMed Ltd., Newcastle-Upon-Tyne NE1 8ST, UK; ${ }^{5}$ Department of Forensic Sciences and Toxicology, \\ Faculty of Medicine; ${ }^{6}$ Laboratory of Clinical Virology, School of Medicine, University of Crete, \\ 71003 Heraklion; ${ }^{7}$ Research Group of Clinical Pharmacology and Pharmacogenomics, Faculty of Pharmacy, \\ School of Health Sciences, National and Kapodistrian University of Athens, 15771 Athens, Greece
}

Received April 20, 2020; Accepted May 18, 2020

DOI: $10.3892 / \mathrm{ijmm} .2020 .4608$

\begin{abstract}
The major impact produced by the severe acute respiratory syndrome coronavirus 2 (SARS-CoV-2) focused many researchers attention to find treatments that can suppress transmission or ameliorate the disease. Despite the very fast and large flow of scientific data on possible treatment solu-
\end{abstract}

Correspondence to: Professor George Mihai Nitulescu, Faculty of Pharmacy, 'Carol Davila' University of Medicine and Pharmacy, 6 Traian Vuia, 020956 Bucharest, Romania

E-mail: george.nitulescu@umfcd.ro

Professor Aristidis Tsatsakis, Department of Forensic Sciences and Toxicology, Faculty of Medicine, University of Crete, 71003 Heraklion, Greece

E-mail: tsatsaka@uoc.gr

Abbreviations: AP2, adaptor protein 2; AMPK, AMP-activated protein kinase; AT1, Ang1-8 receptor 1; ACE2, angiotensin-converting enzyme 2; AAK1, AP2-associated protein kinase 1; BECN1, Beclin1; COVID-19, coronavirus disease 2019; EMA, European Medicines Agency; ExoN, exoribonuclease; $\mathrm{EC}_{50}$, half-maximal effective concentration; $\mathrm{IC}_{50}$, half-maximal inhibitory concentration; IFN, interferon; IL, interleukin; JAK, Janus kinases; MERS-CoV, Middle East respiratory syndrome virus; mAb, monoclonal antibody; MCP1, monocyte chemoattractant protein 1; nsp, non-structural proteins; NAK, numb-associated kinases; ORFs, open reading frames; RBD, receptor binding domain; rhACE2, recombinant human ACE2; RdRp, RNA-dependent RNA polymerase; SNPs, single nucleotide polymorphisms; SPK2, S-phase kinase-associated protein 2; TLR, Toll-like receptor; TNF- $\alpha$, tumour necrosis factor alpha; TMPRSS2, type II transmembrane protease serine 2; FDA, US Food and Drug Administration

Key words: SARS-CoV-2, COVID-19, treatment strategies, drug testing tions, none have yet demonstrated unequivocal clinical utility against coronavirus disease 2019 (COVID-19). This work represents an exhaustive and critical review of all available data on potential treatments for COVID-19, highlighting their mechanistic characteristics and the strategy development rationale. Drug repurposing, also known as drug repositioning, and target based methods are the most used strategies to advance therapeutic solutions into clinical practice. Current in silico, in vitro and in vivo evidence regarding proposed treatments are summarized providing strong support for future research efforts.

\section{Contents}

1. Introduction

2. Virological, genomic, and host aspects related to COVID-19 treatment

3. Pathogenesis

4. Treatment strategies

5. Discussion

\section{Introduction}

The severe acute respiratory syndrome coronavirus 2 (SARS-CoV-2), provisionally named as 2019-nCoV and colloquially known as the coronavirus, is the pandemic-causing pathogen behind coronavirus disease 2019 (COVID-19), which originated in Wuhan, Hubei Province, China in the 4th quarter of 2019 (1). Despite the rapid delivery of the SARS-CoV-2 genome by the group originally recognizing this novel viral pneumonia and the subsequent production of a number of highly specific and sensitive molecular diagnostics for SARS-CoV-2, progress in fighting this disease is balanced by the continued lack of 'quick win' treatments that can suppress 
transmission or ameliorate disease. Of the more than 100 clinical trials evaluating a cadre of approved, or clinical stage antivirals and related compounds, none have yet demonstrated unequivocal clinical utility against COVID-19.

The eventual containment and mitigation of this emerging disease will depend on our exponentially increasing knowledge around SARS-CoV-2 virology, pathology, and cross-species transmission. With viral genome organization resolved in unprecedented speed, molecular pathogenesis and immunopathology related to protein products, modes of transmission, host cell entry mechanism and kinetics, vesicular trafficking, protein and small molecule interaction, biological and replication machinery mechanisms of action, are only beginning to be understood. Likewise, the propensity for deleterious inflammatory responses is episodically studied against SARS-CoV-2 antigen presentation, antigen-specific antibody and cell mediated responses contributing to protective adaptive immunity and the attenuation of disease severity, as well as pulmonary and systemic tissue destruction. Comprehensive interrogation of the viral-human interactome, and associated chemoinformatic analyses $(2,3)$ nevertheless offer hope for the identification of nodal intervention points across the continuum of COVID-19 disease $(4,5)$. As elucidation of these phenomena will undoubtedly incur delays in developing appropriate pharmacological interventions, clinical attention is understandably focused on US Food and Drug Administration (FDA) approved drugs which present putative treatments aligned to our present understanding of SARS-CoV (the agent of 2002-2003 Guangdong Corinavirus epidemic) and Middle East respiratory syndrome virus (MERS-CoV) infections, followed by compounds in clinical, or even late pre-clinical investigation $(6,7)$.

\section{Virological, genomic, and host aspects related to COVID-19 treatment}

SARS-CoV-2 is a pleomorphic, enveloped, positive-sense single-stranded RNA virus [(+)ssRNA] which encodes 15 or 16 replicate-related proteins, 4 or 5 structural proteins and 1-8 group-specific or accessory proteins from the Orthocoronavirinae subfamily, Coronaviridae family, order Nidovirales (8). Coronaviridae are a large family that includes at least four viruses responsible for common colds: four human coronaviruses (HCoV 229E, NL63, OC43, and HKU1) account for up to a third of adult upper respiratory tract infections (9). A phylogenetic tree of alpha-beta coronavirus is presented in Fig. 1.

SARS-CoV-2 shows great phylogenetic similarity to several strains of coronavirus isolated from bats in China, sharing $88 \%$ identity with bat-SL-CoVZC45 and bat-SL-CoVZXC21 which were isolated in Zhoushan, eastern China (10), more than $96 \%$ genomic similarity with BatCoV RaTG13 collected in Yunnan Province (11), and to a lesser extent to SARS-CoV (approximately 79\% homology). By contrast, the camelid-originating MERS-CoV shares approximately 50\% homology to SARS-CoV-2 (10).

Measuring a sizeable $29.8 \mathrm{~kb}$, the SARS-CoV-2 genome is flanked by short $5^{\prime}$ and $3^{\prime}$ highly structured untranslated regions (UTRs) commonplace in RNA viruses and contains at least 14 open reading frames (ORFs) encoding 27 proteins organized in a manner typical of other coronaviruses
(CoVs) (12) (Fig. 2). The first ORFs are translated into two large polyproteins (ppla and pplab) cytosolically processed into the non-structural proteins (nsp) 1-16. These contain the polyprotein-processing protease nsp5, a host RNA restriction factor (nsp1) arresting canonical translation, and collectively function as the viral replicase-transcriptase complex (2) by rearranging rough endoplasmic reticulum (RER) membranes into double-membrane vesicles (DMVs) wherein replication, transcription and virion assembly take place $(13,14)$. The immunomodulatory protein nsp16 is 2'-O-ribose methyl transferase that renders the virus a toll-like receptor (TLR) 7/8 antagonist (15) and is believed to enhance the purported capacity of the virus to evade antiviral interferon-generating cytosolic pathogen associated molecular pattern recognition receptors, such as the double stranded RNA (dsRNA) sensing protein kinase R (PKR) and TLR3, on account of the DMV replication organelle structure (16). An additional protein of key pharmacological interest the RNA-dependent RNA polymerase (RdRp) nsp12, which is the primary target of the so-called directly acting antiviral (DAA) drug family. The remaining ORFs encode the so-called spike (S or SARS-2-S) protein responsible for virus tropism, as well as envelope I, nucleocapsid $(\mathrm{N})$ and membrane $(\mathrm{M})$ structural proteins. The mechanistic role of many of the remaining accessory proteins that are redundant to viral replication remains undetermined (7).

The human angiotensin-converting enzyme 2 (ACE2) cell surface recaptor has been confirmed as the primary cell attachment factor for SARS-CoV-2 (18). This single transmembrane domain protein is expressed at appreciable protein levels on terminal bronchiole as well as type I and II lung alveolar epithelium cells, which aligns with the primary pathology of COVID-19: loss of $\mathrm{O}_{2}$ saturation due to poor pulmonary gas exchange. Likewise, noteworthy ACE2 levels have been reported among enterocytes of the small intestine, arterial, and venous endothelial cells, and arterial smooth muscle cells in most organs, as well as the vagus nerve innervating the lung, heart and digestive system $(19,20)$, which mirror the diversity of symptoms and pathologies associated with COVID-19: diarrhea, myocarditis, fatigue, encephalopathy (headaches, confusion, anosmia, stroke-like symptoms, and seizures). Following cellular attachment, pivotal to cellular entry is the type II transmembrane protease serine 2 (TMPRSS2) which process the SARS-CoV-2-S to expose a cell-membrane fusion peptide (21). Once membrane fusion is achieved, viral RNA is released into the infected host cell to initiate pathogenic responses and viral replication. In a first step, the open reading frame $1 \mathrm{a} / \mathrm{b}(\mathrm{ORF} 1 \mathrm{a} / \mathrm{b})$ of the viral genome is translated to produce the replicate proteins, after which the replicase-transcriptase complex DMVs are assembled. In a second step, the replication complex reverse-transcribes the positive RNA genome into full-length negative-sense RNAs, which in turn template the production of daughter full-length genomes, and a subset of translation-focused mRNAs. These translation-dedicated transcripts contain a common 5 leader sequence cytosolically spliced to downstream genes, which are added by discontinuous synthesis of minus sense subgenomic RNAs templating the positive RNA genome (22).

The genetic variance of SARS-CoV-2 is relatively small compared to other RNA viruses (23), since CoVs possess 


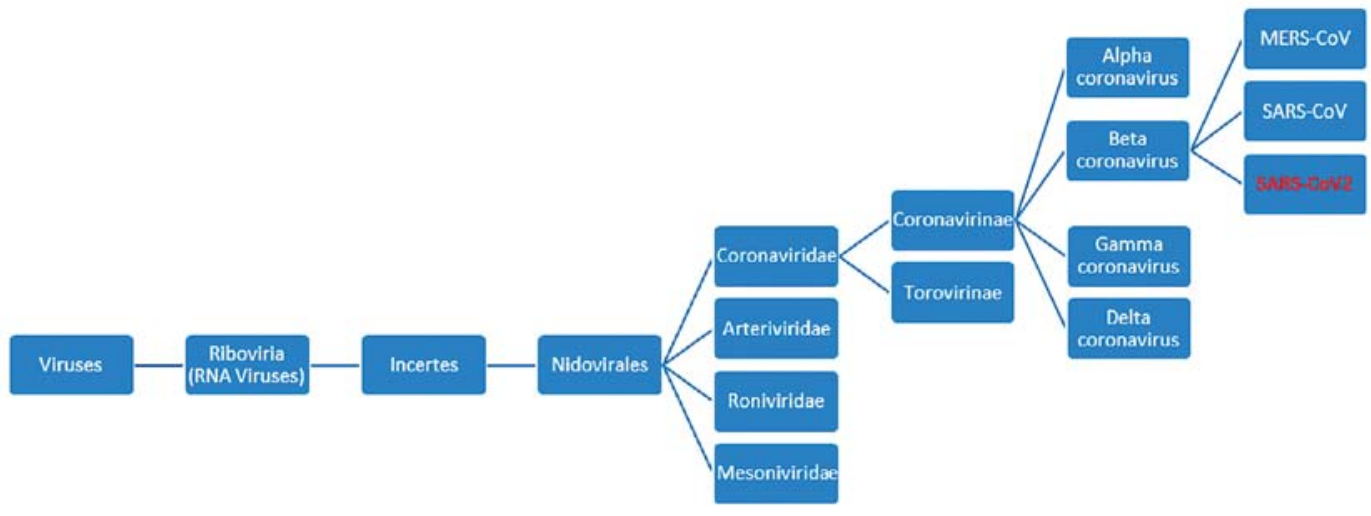

Figure 1. Phylogenetic tree of alpha-beta coronavirus.

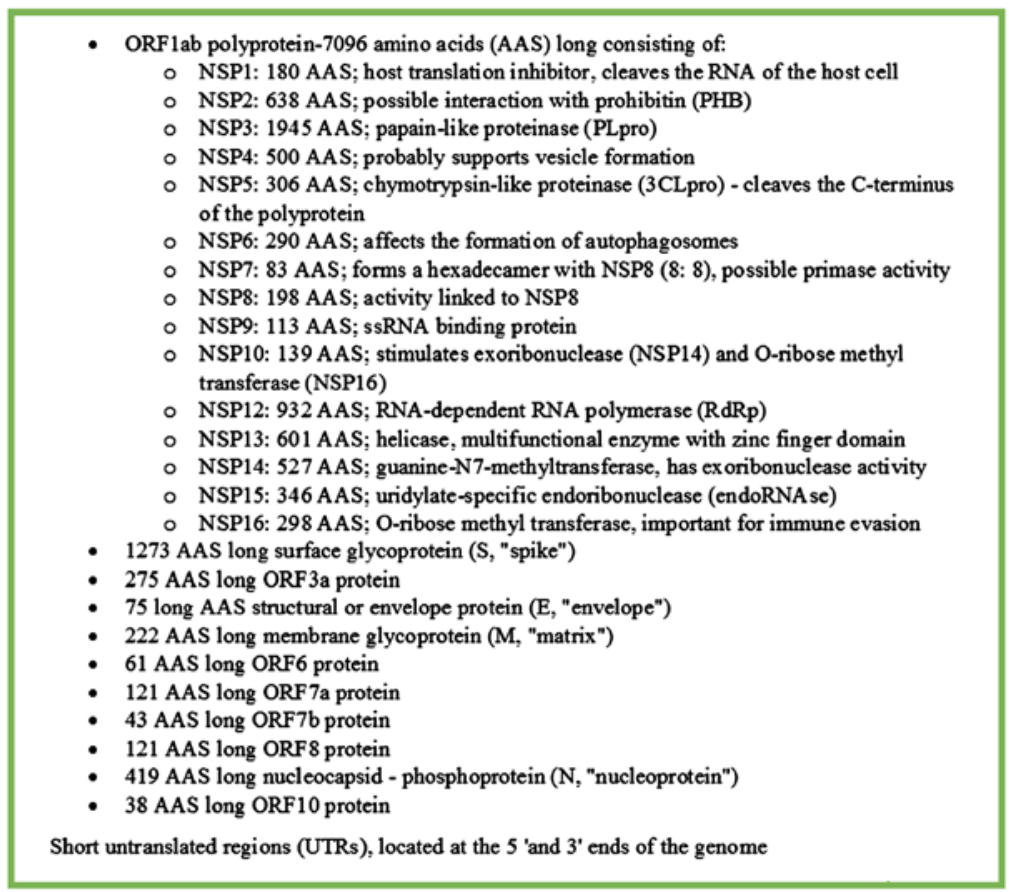

Figure 2. Structure of RNA translation products of SARS-CoV-2 and untranslated regions. Adapted from (17).

mechanisms of transcription error correction through the proofreading function of nsp14 (24), a protein common to MERS-CoV and SARS-CoV, which renders them collectively immune to ribavirin (25), but is also reported to drive recombinatory promiscuity (24). Consequently, ciral quasi-species are relatively suppressed within patients, and mutation primarily leads to single nucleotide polymorphisms (SNPs). Nearly 200 such mutations have been reported as of mid-April 2020 (26). Based on the analysis of more than 100 virus isolates, two main genetic variants of SARS-CoV-2 were initially identified, which are referred to by some members of the community as L-type and S-type, differing only by 2 SNPs. The L-type probably evolved from the S-type and is the more widespread and 'aggressive' variant (27). Another study with 160 virus isolates from different countries classified the virus into $\mathrm{A}, \mathrm{B}$ and $\mathrm{C}$ type, the type $\mathrm{A}$ being the oldest virus variant. Types $\mathrm{A}$ and $\mathrm{C}$ are most common in Europe and America, while type B predominates in Asia (26). More recently, controversy over the transmission propensity of the so-called L-type variant, which harbours the noteworthy D614G mutation on SARS-CoV-2-S (28), has been ascribed to mutation recurrence and multiple geographical introductions as elucidated through the analysis of 7,666 published SARS-CoV-2 genomes (29). However, the impact of these mutations, particularly on protein core to the virus replication cycle such as the cell tropism- and attachment affinity-defining SARS-CoV-2-S remains experimentally undetermined.

The current consensus among the scientific community remains that the main sites of SARS-CoV-2 infection and replication are both the upper and lower respiratory tracts, despite viral loads being consistenly higher, and more reliable to detect in lower respiratory tract speciments. However, this position, largely driven by RT-PCR detection of SARS-CoV-2 and therefore, by extrapolation replication, does not align with the near dearth of ACE2 expression in the upper respiratory tract and oral mucosa (20). The only exceptions to these data are recent reports of olfactory epithelium ACE2 expression in mice (30) which is in line with anosmic symptomatology 
in man, and early evidence of interferon-induced increase in ACE2 expression in upper respiratory tract sites, which would be secondary to infection and replication in either distal, or physiologically non-epithelial local cell types (31). Curiously, endothelial ACE2 expression appears to be ubiquitous even in the upper respiratory tract (20). These findings postulate three hypotheses on the infection and replication cascade of SARS-CoV-2. The simplest of these assumes direct infection of upper respiratory tract epithelia from fomites or large droplets (cough), followed by progressing infection to the lower lung by week 2 , which would explain deteriorating clinical image in cases requiring hospitalization. However, this hypothesis would rely on transcytotic epithelial mechanisms delivering SARS-CoV-2 to ACE2-expressing basal upper respiratory/oral epithelial cells or endothelia (20). Though transcytotic mechanisms are not implausible $(32,33)$, these cells would in turn propagate the virus locally, causing interferon-induced ACE2 epithelial overexpression, epithelial cell infection, and luminal virus shedding, ultimately leading to the observations of low-level detection in nasopharyngeal and oropharyngeal swabs by RT-PCR. However, the immunomodulatory capacity of SARS-CoV-2 manifest through DMVs and nsp16 $(13,14,16)$, in addition to the consistently higher viral load in the lower respiratory tract as opposed to the relatively virus-free upper respiratory tract strongly disfavour this hypothesis. The second hypothesis would require direct infection of the olfactory epithelium again by fomites or droplets, local replication and retrograde transport to the lower lung, whereupon the virus would establish disease-causing replication. However, the infrequent incidence of anosmia coupled to the opposite direction of travel for tracheobronchial mucocilliary clearance, and the need for sub-3 micron aerosol particle dimensions to access the alveoli that would have to be generated in the nose, present a formidable set of physiological barriers to the virus for accessing the lower lung. The last hypothesis would require direct infection of the lower respiratory tract through inhalation of SARS-CoV-2 containing aerosols, directly infecting the ACE2-overexpressing alveoli, sequentially driving upper respiratory tract infection through mucocilliary clearance and aerosol generation in exhaled breath. Poignantly, this putative infection progression sequence aligns with ACE2 protein expression data, SARS-CoV-2 levels reported by RT-PCR across the respiratory tracts of patients, and offers a mechanistic explanation for the rarity of anosmia and low nasopharyngeal carriage of the virus, as diminishing quantities of aerosolized virus would need to diffuse into the mucous found in these tissues upon exhalation. Critically, data documenting viral particle production in upper respiratory tract (or oral) epithelial or indeed endothelial cells remain elusive from both human and animal studies.

\section{Pathogenesis}

Even though the replication site of the virus is admittedly the lower respiratory system the virus can affect the function of secondary organs that also express ACE2, such as the kidney, GI tract, liver, and gall bladder. Typically, this results in symptom severity that drives patients to seek medical attention, usually by week 2 after symptom onset. However, to date no single clincal report has documented measurable, or at least appreaciable amounts of virus in the peripheral blood of patients admitted with COVID-19. One possible explanation of the practically undetectable levels of SARS-CoV-2 in blood might be the arrival time of patients to hospitals (week 2), by which time seroconversion and neutralizing antibodies are being generated and thus viraemia suppressed. Alternatively, endothelial ACE2 expression reduces blood viral load below the limit of detection of RT-PCR $(\sim 15,000$ copies/ml whole blood) by sequestering free viral particles from suspension. However, such extent of ACE2 expression systemically across endothelia is not corroborated in public protein expression data repositories (e.g., https://www.proteinatlas. org/ENSG00000130234-ACE2/tissue), nor is it physiologically evidenced by the loss of endothelial barrier function as is common in haemorrhagic fever viral infections. Taken together, these findings cast doubts on hypotheses regarding the mechanism of transfer of SARS-CoV-2 from the respiratory tract to the intestines (34), which is manifested through faecal detection of SARS-CoV-2 RNA (35) and protein in lower GI tract (36). By stark contrast, the main sites of ACE2 expression, i.e., the lung, GI tract, kidneys, liver and gallbladder, and indeed the testis in men, wherein SARS-CoV-2 replication has also been documented (37), are all innervated by the vagus nerve.

The median time from symptom onset to acute respiratory distress syndrome, the principal reason for COVID-19 patients seeking medical attention, is approximately 8 days; around this timepoint COVID-19 appears to morph from an acute viral infection to what might appear to be a second attack, causing the patient's condition to worsen over the second week after symptom onset. Critically, continued deterioration beyond day 14 is associated with high mortality. Thus the disease could be divided into three major stages after symptom onset: in the first stage symptomatic patients report initially mild-to-moderate, but quality of life impacting non-specific symptoms (days 0-7) associated with a progressive drop in viral load; stage II, wherein severe dyspnoea and associated pneumonia drive patients to seek medical attention; and, finally stage III, a severe respiratory symptomatic stage potentially with high viral load, but most commonly characterised by runaway inflammatory responses associated with multiple organ failure $(38,39)$.

Thus, the ensuing innate immune response might be two-phased; instead of the early innate immunity containing the virus towards the developement of adaptive immunity, in some patients there would appear to be a loss of key checkpoint functions driving a secondary, damaging inflammatory phase. The second inflammatory phase is driven by the cytokine release syndrome (the so-called 'cytokine storm') and affects patients with severe conditions. Although genetic differences may underpin innate response amplitude between individuals, viral amplification appears to ensue (40) causing direct or, more likely, indirect destruction of tissues affected by the so-called 'happy hypoxia' associated with COVID-19, the otherwise asymptomatic critical reduction of blood oxygen saturation below $95 \%$, sometimes reportedly as low as $50 \%$, i.e., well below the level normally associated with respiratory arrest.

The early antibody response against SARS-CoV-2 including $\operatorname{IgA}$, IgM, and $\operatorname{IgG}$ response was examined by using an ELISA-based assay on the recombinant SARS-CoV-2 
protein against the recombinant proteins for the other four common cold-causing human coronaviruses. The median time to $\operatorname{IgM}$ and $\operatorname{IgA}$ antibody detection was 5 days with interquartile range (IQR) 3-6, while IgG was detected on 14 days (IQR 10-18) after symptom onset, with a positive rate of 85.4 , 92.7 and $77.9 \%$, respectively (41). In a study of 23 patients with COVID-19, viral load was reported to be declining across the first week of illness, dropping below detection limits amongst most patients by week 2 . With analytical sensitivity lacking between days 7-10, IgG and $\operatorname{IgM}$ antibodies were detectable more reliably at approximately 10 days after symptom onset, with most patients seroconverting within the first 3 weeks. Importantly, both $\operatorname{IgG}$ and $\operatorname{IgM}$ were observed to neutralize SARS-CoV-2-N and the recaptor binding domain of SARS-CoV-2-S (42).

Research data on late humoral response and persistence of neutralizing antibodies in SARS-CoV-2 infection is still limited. A major cause for concern are reports in China, Japan and South Korea of patients testing still positive by RT-PCR days, or even weeks after clinical discharge presumably on the basis of two consecutive negative RT-PCR results. Some patientsa are even reported to relapse, indicating that a sustained immune response may be difficult to obtain, or that at least humoral immunity is inadequate for infection elimination (40). Although the World Health Organization (WHO) has recently pronounced these observations as a consequence of RNA shedding from infected apoptotic epithelia in the respiratory tract, corroborating data in the literature are lacking. On the other hand, patients who have recovered from SARS-CoV have been reported to harbour potent antibody responses to SARS-S protein and its receptor binding domain (RBD) for at least three years, indicating that RBD-targeting vaccines under development might be adequately protective against COVID-19 (43,44).

Another aspect meriting attention is the progressive lymphopenia documented during COVID-19, which is principally manifest and most pronounced in severe cases, affecting $\mathrm{CD}^{+}$and $\mathrm{CD}^{+} \mathrm{T}$ cell levels, as well as B lymphocyte concentration, potentially adversely affecting antibody production. Thus, T cell lymphopenia and associated cytokine concentrations have been proposed as biomarkers of poor prognosis, with interleukin (IL)-6, IL-10, and D-dimer continued elevation marking transition to a severe disease state between days 7-14 after symptom onset, followed by further elevation of D-dimer, neutrophilia, blood urea nitrogen, and creatinine marking in the later, irreversible stages of disease. In contrast, IL-8 and tumor necrosis factor alpha (TNF- $\alpha$ ) elevation appears to be associated and indeed peak early during the recovery phase $(45,46)$.

\section{Treatment strategies}

In the absence of a clinically proven treatment for COVID-19, frontline clinicians are restricted to offering supportive symptomatic treatment such as oxygen therapy, steroids on a per case basis, fluid management, and broad-spectrum antibiotics against co- or secondary bacterial infections (45). Beyond these, as with any viral disease, therapeutic intervention may extend to either direct acting antivirals (DAAs) or immunomodulatory adjuvants and substances (47). Considering the drug discovery process, research efforts can be grouped in three major classifications. The first relies on the repurposing of approved, broad-spectrum antiviral drugs, through clinical trial and error. The major advantage of this approach consists of the clear knowledge about the drugs' metabolic profile, dosages needed and supported, potential side effects, and risks. The disadvantage of these types of drugs is represented by their low selectivity and, often, poor utility between virus families. The second strategy is based on high-throughput screening, in silico, in cellulo or, more recently, by means of artificial intelligence drug discovery, to identify approved, or, at best, late stage drugs with promising therapeutical effects either through their intended mode of action (e.g., RNA dependent RNA polymerase inhibition), or through their well-described off-target effects (similar to kinase inhibitor promiscuity). The third strategy involves identifying the molecular and pathological characteristics of the disease in question, to develop entirely novel drugs that may target them. The advantage here would be the high selectivity and potentially high efficacy (48). Thankfully, the 18 years of head start knowledge gained against SARS-CoV-2 on the back of the SARS-CoV and MERS-CoV outbreaks of the early 21 st century, have resulted in an unprecedented speed by which the molecular mechanisms of SARS-CoV-2 infection are being elucidated, not least because of the rapid elucidation of the genomic organization of SARS-CoV-2. These datasets have informed several rational, high confidence potential therapeutic targets against SARS-CoV-2 (10,49) (Fig. 3).

As the development of new drugs is a long and costly process, the urgency of the pandemic targeted early efforts on identifying candidate treatments among marketed drugs or approved, but later abandoned compounds. Drug repurposing, also known as drug repositioning, is one of the best solutions to identify therapeutic solutions for COVID-19 in a time-critical fashion (50).

Blocking virus cell entry. Penetration of host cells is an obligatory step in the life of any virus rendering it a powerful target for drug development (51). The discovery of the intrinsic mechanism of SARS-CoV-2-S to mediate cell entry focused efforts on ACE2 and the whole renin-angiotensin-aldosterone system (RAAS) $(18,51)$. ACE2 is monocarboxypeptidase that hydrolyzes the bond between the carboxyl-terminal phenylalanine and proline in angiotensin II (Ang1-8) generating Ang1-7, a physiological antagonist of Ang1-8 with vasodilator and anti-inflammatory properties (52). Considering these effects, a soluble recombinant human ACE2 (rhACE2) was developed under the name APN01 (known also as GSK2586881) and evaluated in patients with pulmonary arterial hypertension (53) and acute pulmonary injury (54). In healthy volunteers rhACE2 was administered intravenously in doses from 100 to $1,200 \mu \mathrm{g} / \mathrm{kg}$ and was generally well-tolerated, with no significant effect on blood pressure and heart rate, and with only mild or moderate adverse events reported (52).

SARS-CoV-2-S engages ACE2 as the entry receptor in a similar way as the homologous SARS-CoV spike protein. The expression and distribution of the ACE2 on alveolar epithelial cells is consistent with the dry cough and dyspnea experienced by the patients. Consequently, it is anticipated that rhACE2 may act as a competitive interceptor of SARS-CoV-2 thereby reducing cell penetration and offering protection 


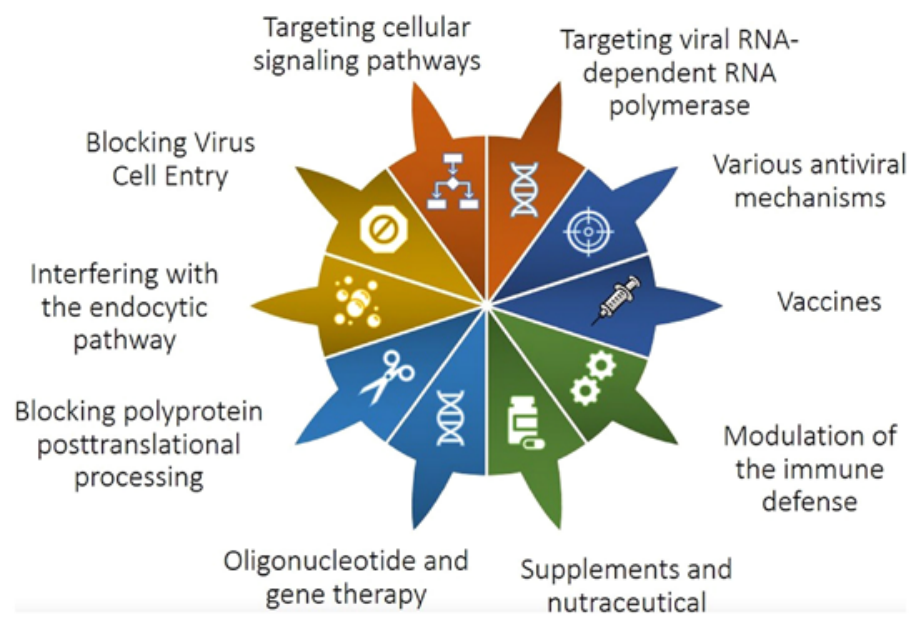

Figure 3. Major therapeutical strategies in COVID-19.

against infection (55). A randomized placebo-controlled study (NCT04335136) is scheduled to test rhACE2 in SARS-CoV-2 patients (56). Furthermore, several peptide derivatives of ACE2 were designed using molecular dynamics simulations as potential decoys that could be used as future inhaled therapeutics (57). However, drug development history (inhaled insulin, Exubera) denotes the brief residence time of soluble proteins in the respiratory lumen, necessitating modifications (58) that would sustain rhACE2 decoy potency at the primary infection site of interest for SARS-CoV-2, the respiratory epithelium.

Another strategy focused on ACE2 is based on the hypothesis that ACE2 activity is reduced by SARS-CoV-2-S, exposing the organism to higher levels of Ang1-8 which increases alveolar permeability and causes lung injury (59). Two compounds, resorcinolnaphthalein and 1-[(2-dimethylamino)ethylamino]-4-(hydro xymethyl)-7-[(4-methylphenyl)sulfonyloxy]-9H-xanthene-9-one, were identified in a large docking study as ACE2 activators and were demonstrated to enhance ACE2 activity in a dose-dependent manner, albeit with half-maximal effective concentration $\left(\mathrm{EC}_{50}\right)$ values of $19.5 \pm 0.4$ and $20.1 \pm 0.8 \mu \mathrm{M}$, respectively (60). Diminazene aceturate is a veterinary-approved antitrypanosomal drug that similarly activates ACE2 at comparable in vitro $\mathrm{EC}_{50}$, rendering protective effects in cardiovascular and type 1 diabetes experimental models $(61,62)$. A recent review study presents the toxic effect of diminazene aceturate on the nervous system of some animals, but provides evidence that it was safe in thousands of trypanosomiasis patients from Uganda (62). These compounds could be a potential therapy in patients with SARS-CoV-2, provided topical dosing and pharmacology afford adequate activation of respiratory ACE2.

Likewise, use of Ang1-8 receptor 1 (AT1) antagonists to reduce the aggressiveness and mortality of SARS-CoV-2 infection based on two mechanisms, the blockade of the effects of excess Ang1-8, and the upregulation of ACE2 (63). Several clinical studies are underway to asses various AT1 antagonists: losartan $25 \mathrm{mg}$ once daily (NCT04335123, NCT04328012, and NCT04311177) or $50 \mathrm{mg}$ daily (NCT04312009), losartan $100 \mathrm{mg}$ once daily alone or in combination with aspirin $150 \mathrm{mg}$ once daily or simvastatin $80 \mathrm{mg}$ once daily in an eight arms factorial trial (NCT04343001), telmisartan $80 \mathrm{mg}$ twice daily (NCT04355936), valsartan $80 \mathrm{mg}$ up to $160 \mathrm{mg}$ (NCT04335786) (56).
Camostat is an orally active serine protease inhibitor of trypsin and various inflammatory proteinases including plasmin, kallikrein, thrombin and urokinase (64). It is approved clinically as mesylate salt in Japan, but not Europe or the USA, for the treatment of chronic pancreatitis and postoperative reflux esophagitis due to its ability to inactivate trypsin and prevent autodigestion (65). Camostat mesylate has demonstrated inhibitory activity against TMPRSS2 and other cell-surface proteases involved in SARS-CoV activation (66). Indeed TMPRSS2 emerged as a promising antiviral drug target after it was identified to have a pivotal role for viral pathogenesis of monobasic H1N1, H3N2 and H7N9 influenza A viruses (67).

Exposure of human bronchial epithelial Calu-3 cells to $10 \mu \mathrm{M}$ camostat mesylate was reported to cause a 10 -fold decrease in SARS-CoV viral entry and a 13-fold decrease in SARS-CoV replication (66). Although from a virology perspective such inhibitory effects are considered mediocre, animal experiments in BALB/c mice at $30 \mathrm{mg} / \mathrm{k}$ administered orally twice daily for 9 days starting $10 \mathrm{~h}$ before SARS-CoV inoculation increased survival rate to $60 \mathrm{vs.} 0 \%$ for untreated animals (65). Similarly, Calu-3 cells pre-incubated with camostat mesylate at very high concentrations $(100 \mu \mathrm{M})$ before infection with SARS-CoV-2 significantly reduced, but failed to abrogate Calu-3 infection with SARS-CoV-2 as measured by SARS-CoV-2-specific RT-PCR (21). Thus, a randomized, placebo-controlled, phase IIa clinical trial (NCT04321096) is evaluating camostat mesylate at $200 \mathrm{mg}$ x 3/day for 5 days as treatment for SARS-CoV-2. However, it is noteworthy that the study design of this trial fails to meet the pre-treatment or, at least, early treatment requirement common to most efficacious antivirals and indeed the in vitro and in vivo performance requirements exhibited previously. Elsewhere, the CLOCC-2020 clinical study (NCT04338906) will evaluate the efficacy and safety of camostat mesylate in combination with the controversial agent hydroxychloroquine in hospitalized patients with moderate COVID-19 infection (56).

Nafamostat, a chemical analog of camostat, has potent inhibitory effects on several types of serine proteases including trypsin, thrombin and plasmin (68) and was identified to effectively reduce the MERS-CoV viral entry 
in Calu-3 cells at the physiologically relevant concentration of $1 \mathrm{nM}$ (69). Nafamostat at $100 \mu \mathrm{M}$ demonstrated promising inhibitory effects against SARS-CoV-2 infection of Vero E6 cells (70), but it is anticipated that its very short half-life (71) significantly hinders clinical utility in preventing SARS-CoV-2 infection.

Bromhexine, a widely used mucolytic cough medicine, was identified as a TMPRSS2 inhibitor in a screening on various chemical libraries, including over 1,200 FDA approved drugs. With an $\mathrm{IC}_{50}$ of $0.75 \mu \mathrm{M}$, inhibition was reported as selective, with low effects on the related hepsin and matriptase proteases (72). However, preliminary data on influenza-infected Calu-3 cells treated with bromhexine showed no inhibitory effect (73). Despite a lack of in vitro or in vivo data on SARS-CoV-2, it has been proposed as a solution for COVID-19 patients based on its effect on TMPRSS2 and favorable pharmacokinetic and safety profile (74). Several clinical trials are registered to evaluate bromhexine as prophylaxis or therapy in COVID-19 patients using various drug combinations (NCT04355026, NCT04340349, NCT04273763) (56).

Aprotinin is a natural 58 amino acid peptide and a serine protease inhibitor that blocks fibrinolysis and reduces bleeding. It demonstrated significant effects against influenza viruses (75). Preliminary research reports have demonstrated that in $\mathrm{Caco} 2$ cells aprotinin is more potent against SARS-CoV-2 $\left(\mathrm{EC}_{50}=22.9 \mathrm{KIU} / \mathrm{ml}\right)$ than against SARS-CoV $\left(\mathrm{EC}_{50}=118 \mathrm{KIU} / \mathrm{ml}\right)$ cytopathogenic effects $(76)$ as measured in kallikrein inactivator units (KIU). To this date, no clinical test has been registered in Clinical Trials databases (56).

SARS-CoV nucleocapsid (protein N) binds to cyclophilin A, which subsequently interacts with a member of the immunoglobulin family of receptors, HAb18G/CD147, on the cell membrane leading to viral cell invasion (77), in a mechanism similar with that of HIV-1 virus (78). Based on this model, a humanized anti-CD147 antibody was clinically tested in 17 patients with SARS-CoV-2 (NCT04275245) and published in a preliminary fashion (79). Whilst the results are interesting, interpretation should be approach with caution as the source and characteristics of the antibody, 'meplazumab', are missing, and the number of tested patients is very low.

Clathrin-mediated endocytosis is another mechanism described for SARS-CoV cell invasion and possibly utilized by SARS-CoV-2. Chlorpromazine inhibits the relocation of clathrin and the adaptor protein 2 (AP2) from the cell surface, significantly inhibiting SARS-CoV entry into HepG2 cells at the relatively high concentration of $20 \mu \mathrm{M}$ (80). Unfortunately, it showed no significant effect on the SARS-CoV-2 cytopathic effects in Vero E6 cells when tested at $100 \mu \mathrm{M}(81)$, yet a clinical trial is scheduled to test the effect of $25 \mathrm{mg}$ chlorpromazine administrated intravenously every $6 \mathrm{~h}$ for 1 week (NCT04354805) (56).

An artificial intelligence method identified members of the numb-associated kinases (NAK) family as potential therapeutic targets against SARS-CoV-2 (82). The AP2-associated protein kinase 1 (AAK1) is an important member of NAK that binds to clathrin and phosphorylates the medium subunit of AP2, playing an important role in regulating clathrin-mediated endocytosis $(83,84)$ and its inhibition was demonstrated to reduce the infectivity of a wide range of viruses (82). The chemically related pyrazole-pyrolopyrimidine derivatives baricitinib and ruxolitinib are clinically approved Janus kinase (JAK) inhibitors with important inhibitory effects on AAK1 (85), likewise predicted to reduce SARS-CoV-2 infection (82). A clinical trial (NCT04348071) is programmed to evaluate ruxolitinib in patients receiving $10 \mathrm{mg}$ twice daily for 14 days and a similar trial (NCT04340232) will test baricitinib administered $2 \mathrm{mg}$ once daily for 14 days (56).

The role of cathepsins in coronavirus entry has been established for SARS-CoV and MERS-CoV. In order to investigate their role in SARS-CoV-2 cell entry a pseudovirus model was tested in ACE2-expressing 293 cells. While cell treatment with the cysteine protease cathepsin B inhibitor CA-074 $(30 \mu \mathrm{M})$ had no significant effect, cathepsin L inhibitor (SID 26681509, $2 \mu \mathrm{M}$ ) treatment reduced viral entry up to $76 \%$. An inhibitory effect close to $93 \%$ was reached after treatment with E64d $(30 \mu \mathrm{M})$, an inhibitor of calpain and cathepsin B, H and L (86). Cathepsin $\mathrm{L}$ is an attractive target for drug development in several diseases, but despite all the efforts, no cathepsin $\mathrm{L}$ inhibitor has advanced to clinical trials (87) making future cathepsin L-based SARS-CoV-2 therapies improbable.

Interfering with the endocytic pathway. Most viruses use endocytic entry mechanisms and for the majority of them, a reduction of $\mathrm{pH}$ serves as a cell penetration trigger (88). Earlier studies have described that endocytic $\mathrm{pH}$ modification suppresses viral replication and may also have a virucidal effect. Such a minimal $\mathrm{pH}$ value change, with no negative impact on the patient's health status, could be achieved by administering a simple small molecule with hydrophobic weak base properties, like ammonium chloride, which would lead to endocellular alkalosis by accumulating in lysosomes following diffusion through plasma and lysosomal membranes. Weak bases and ionophores, like ammonium chloride, chloroquine, or monensin are frequently used in experimental studies of viral cell penetration mechanisms (89). Ammonium chloride treatment strongly inhibited the entry of pseudotypes bearing SARS-2-S in 293T cells lacking TMPRSS2, but was less efficient in Caco-2 cells (TMPRSS2 ${ }^{+}$) (21).

Chloroquine, chemically known as 7-chloro-4-((4-(diethy lamino)-1-methyl butyl)amino)quinoline, is a 9-aminoquinoline widely used for the treatment of malaria, amebiasis and several auto-immune diseases (90) recently proposed to be efficient in inhibiting SARS-CoV-2 in infected cells $(70,91)$. Chloroquine has already demonstrated in the past in vitro anti-viral activity against several types of both RNA and DNA viruses, such as rabies virus, poliovirus, several influenza virus types, hepatitis A, B and C viruses, Dengue virus, Zika virus, and many others (92), as well as SARS-CoV (93) and MERS-CoV (94). The general anti-viral mechanism of action relates to the ability of chloroquine, as a weak base, to increase the endosomal $\mathrm{pH}$ required for viral/host cell fusion, preventing endocytosis, and to interfere with viral particles bound to the cell surface membrane (95). Additionally, in the case of SARS-CoV and SARS-CoV-2, chloroquine is proposed to inhibit the glycosylation of ACE2 receptor chains, thus limiting ligand recognition of these receptors, rendering the viral spike protein unable to mediate cell entry (92).

In light of the new pandemic, several clinical trials have been conducted in different countries in order to test the safety 
and efficacy of chloroquine phosphate in treating SARS-CoV-2 patients (96), with results confirming a significant improvement when compared to control groups, as in the case of clinical trial ChiCTR2000029609 (97). When confronted with the recent COVID-19 crisis in China, chloroquine has even been included in the national treatment guidelines, with Chinese clinicians recommending $500 \mathrm{mg}$ chloroquine twice daily for 10 days for the treatment of mild, moderate and severe cases of SARS-CoV-2-related pneumonia with no contraindications to the drug (98).

Hydroxychloroquine is a less-toxic derivative of chloroquine also used as an anti-malarial and in the management of auto-immune disease, proposed through in vitro studies to act also on SARS-CoV-2 infected cells (91). In Vero E6 models hydroxychloroquine presented a better antiviral effect with EC50 values of $6.14 \mu \mathrm{M}$ (after $24 \mathrm{~h}$ ) and $0.72 \mu \mathrm{M}$ (after $48 \mathrm{~h}$ ), compared with chloroquine values of $23.90 \mu \mathrm{M}(24 \mathrm{~h})$ and $5.47 \mu \mathrm{M}(48 \mathrm{~h})(91)$.

Similar to chloroquine in many aspects with the exception of a better pharmacotoxicological profile, hydroxychloroquine is more frequently used instead of chloroquine in COVID-19 clinical trials (99). Several studies confirmed hydroxychloroquine sulfate administration to be significantly associated with a reduction of the viral load in SARS-CoV-2 infected patients, as in the case of the Chinese randomized clinical trial reported by Chen et al (ChiCTR2000029559) (100) and Gautret et al, who also reported after 6 days of treatment apparently significant benefits compared to negative controls when administering daily $600 \mathrm{mg}$ hydroxychloroquine in association with azithromycin, where necessary (101). The drug is currently perceived in certain quarters to be more promising than chloroquine as a COVID-19 treatment due to the reduced probability of causing retinopathy, psychiatric disorders, or severe cardiovascular adverse effects such as arrhythmia (99); however, self-medication using both drugs is unadvisable, as 9-aminoquinolines possess a narrow therapeutic window (102) and are associated with QT prologation. Currently, larger studies with a more flexible design investigate the effect of hydroxychloroquine, with the Solidarity study (EudraCT no. 2020-000982-18) and the Discovery study (NCT04315948) randomizing treatment of SARS-CoV-2-infected patients using different antiviral drugs, including hydroxychloroquine (103). However, preliminary reports are highlighting a 2.61 adjusted hazard ratio of death among COVID-19 patients treated with hydroxychloroquine alone in the absence of azithromycin, and no reduction in the risk of mechanical ventilation (104).

Blocking polyprotein posttranslational processing. Another promising strategy of treatment appears to be interfering with viral replication, especially by acting at key points following translation. After synthesis, the two newly-formed viral polyproteins ppla and pplb require for posttranslational processing two important proteinases encoded in these chains of amino acids: papain-like proteinase, PLpro, and chymotrypsin-like proteinase, 3CLpro, often referred to as the main protease or $\mathrm{M}^{\mathrm{pro}}$ (3). The activity of these two cysteine proteases is essential for generating the 16 non-structural proteins, critical to the formation of the replicase complex, and it is known that inhibiting the activity of either of these two proteases affects the replication of SARS-CoV-2 $(3,105)$.
Several inhibitors acting on SARS-CoV main protease, which displays $96 \%$ similarity to the SARS-CoV-2 $M^{\text {pro }}$ (106), have recently been synthesized and tested both in enzymatic assays and in cell lines, showing promise for developing future drugs. Recently, Zhang et al, after structure-based drug design and optimization of different dipeptide $\alpha$-ketoamides, derived several potential $\mathrm{M}^{\text {pro }}$ inhibitors, of which $(S)$-N-Benzyl-3-((S)-2-cinnamamido-3cyclohexylpropanamido)-2-oxo-4-((S)-2-oxopyrrolidin-3-yl) butanamide (referred to as 11r) displayed physiologically relevant (nM) antiviral activity against MERS- $\mathrm{CoV}$ and SARS-CoV in hepatic (Huh7) but not routine virology (Vero E6) cell lines, as well as good inhibition of the SARS-CoV protease in enzymatic assays (107). Based on previous research, the same study group obtained a pyridone-containing $\alpha$-ketoamide derivative of 11r, a compound (referred to as 13b) with even lower sub-micromolar concentrations against SARS-CoV-2 $\mathrm{M}^{\text {pro }}$ in enzymatic assays, with half-maximal inhibitory concentration $\left(\mathrm{IC}_{50}\right) 0.67 \pm 0.18 \mu \mathrm{M}$, and low-micromolar $\mathrm{EC}_{50}$ values (4-5 $\mu \mathrm{M})$ in Calu-3 cells, further obtaining favorable results in mouse studies in terms of pharmacokinetic parameters, reflecting lung tropism after either subcutaneous or topical administration (108).

Drug repurposing appears to be another interesting method of identification of $\mathrm{M}^{\mathrm{pro}}$ inhibitors. Most notable drugs showing inhibition of the main protease of SARS-COV-2 were found to be several anti-retroviral agents approved for HIV-1 treatment.

Lopinavir is a selective HIV-1 protease inhibitor orally administered in combination with ritonavir, a CYP3A4 inhibitor used to increase its plasma concentration and clinical efficacy (109). Lopinavir was tested against SARS-CoV and showed a moderate activity in Vero-E6 cells (110). In a preliminary, not yet peer-reviewed, study in Vero E6 cells, lopinavir showed a mediocre $\mathrm{EC}_{50}=5.73 \mu \mathrm{M}$ against SARS-CoV-2 (111). A recent clinical trial investigating the safety and efficacy of lopinavir $(400 \mathrm{mg})$ and ritonavir $(100 \mathrm{mg})$ effect in 99 patients infected with SARS-CoV-2 has already ended, unfortunately concluding that the administration of these drugs showed no significant benefit comparing to current standard care (112). The ineffectiveness of this combination could be explained by the delayed treatment initiation, the median time from symptoms identification to therapy onset being 13 days (51). Whether the ineffectiveness of the treatment was due to the late therapy start or because of low efficient concentrations at the site of action remains to be explored.

The clinical use of lopinavir/ritonavir is additionally linked to nausea and diarrhea (up to $28 \%$ ) as well as hepatotoxic effects $(2-10 \%)$. Despite the limited data to support use in the treatment of COVID-19, there is an important number of clinical studies registered to test the lopinavir $(400 \mathrm{mg})$ and ritonavir $(100 \mathrm{mg})$ coformulation alone or in combination with hydroxychloroquine or interferon $(51,56)$.

Other HIV-1 protease inhibitors, such as amprenavir, tipranavir, saquinavir, ritonavir, nelfinavir, indinavir, darunavir, and atazanavir that have been predicted to inhibit SARS-CoV-2 $M^{\text {pro }}$ (113) were also tested on Vero E6 cells infected to SARS-CoV-2. Among these, nelfinavir was observed to be the most efficient, with a mediocre $\mathrm{EC}_{50}$ of $1.13 \mu \mathrm{M}$ suppressing viral replication in the post-entry step (111). In a similar study on SARS-CoV, nelfinavir inhibited the viral replication 
at non-toxic doses with a selectivity index (SI) close to 300 , while ritonavir, lopinavir, saquinavir, and indinavir, did not have a significant effect (114). Saquinavir and tipranavir showed mediocre replication inhibition against SARS-CoV-2 in cell lines $\left(\mathrm{EC}_{50}=8.83 \mu \mathrm{M}\right.$, respectively 13.34), although with a lower selectivity index, while amprenavir, darunavir and indinavir had low effects on viral replication with $\mathrm{EC}_{50}$ values over $30 \mu \mathrm{M}$ (111). Another preprint publication reports the SARS-CoV-2 viral replication inhibition by atazanavir with $\mathrm{EC}_{50}$ values of $2.0 \pm 0.12 \mu \mathrm{M}$ (115).

No clinical study is registered in the Clinical Trials database, nor in the Chinese Clinical Trial Registry to test atazanavir, nelfinavir, tipranavir, or saquinavir as COVID-19 therapies. The clinical trials NCT04252274, NTC04303299 and NCT04366089 will test darunavir in association with other antivirals (56).

Targeting viral RNA-dependent RNA polymerase. The RNA-dependent RNA polymerase ( $R d R p)$ is the central subunit of the RNA synthesizing process for all positive-strand RNA viruses and therefore an attractive target for antiviral inhibitors. In SARS-CoV-2 nsp12 functions as RdRp (116) and plays a central role in the viral replication and transcription by catalyzing the synthesis of viral RNA, assisted by nsp7 and nsp8 that serve as co-factors (117). The polymerase of RNA viruses is prone to replication mistakes, lacking the proofreading capacity of its analog from DNA viruses. This high mutation rate $\left(10^{-3}\right.$ to $10^{-5}$ mutations/nucleotide/round of replication) enables RNA viruses to better adapt to environmental changes, but also introduces damaging mutations that corrupt essential functions, a process called lethal mutagenesis $(118,119)$.

In CoVs, nsp14 has both 3'-5' exoribonuclease (ExoN) and guanine-N7-methyltransferase (N7-MTase) functions. ExoN can hydrolyze RNA acting as a proofreading enzyme that is capable of removing mismatched nucleotides (120). Targeting viral RNA-dependent RNA polymerase has proven a successful strategy in treating various viral infections (121), but is difficult in the case of CoVs because of the ExoN activity $(116,119)$. Importantly, the catalytic site of RdRp shares structural similarities with the hepatitis $\mathrm{C}$ virus (HCV) ns5b RdRp (117), introducing the prospect of repurposing ns5b HCV antivirals as COVID-19 therapies. The results of a docking study indicate that tenofovir and sofosbuvir, two approved HCV antivirals, can bind tightly to SARS-CoV-2 RdRp (122). Still, these results should be view with caution considering their effect could be theoretically easily reversed by nsp14 activity. It is thus hypothesized that finding inhibitors of ExoN activity could be a future direction for COVID-19 therapeutics (119).

A number of compounds with proven inhibitory effects on other virus RdRps were tested against SARS-CoV and SARS-CoV-2, triaging some of them to clinical evaluation. Ribavirin has the advantage of being clinically approved, but is associated with important side effects and low efficacy. By contrast, remdesivir, and to a lesser extent, favipiravir and galidesivir, look like the most promising RdRp inhibitors for a future COVID-19 solution.

Remdesivir, formally known as GS-5734, is a 2-ethylbutyl-L-alaninate phosphoramidate prodrug that generates the active compound, GS-441524, a 4-amino-5-cyano-pyrrolotriazine analog of adenosine (123). Remdesivir is metabolized more efficiently than its metabolite GS-441524 into the active nucleoside triphosphate that function as a chain-terminating nucleotide analog blocking RdRp (116). Remdesivir is not approved by the FDA and not by the European Medicines Agency (EMA), but recently received FDA emergency use authorization for the treatment of COVID-19 on the basis of reduced hospitalisation time (124). However, this outcome is not without controversy as the trial primary endpoint was altered days before outcome announcement, raising important concerns with respect to utility under the purported mechanism of action. Given the structural similarity of remdesivir to naturally occurring 2'-O-methyl nucleoside analogues, antagonists of toll like receptor 7 , and the initiation of treatment with the pre-symptomatic/early symptomatic optimal treatment window, it is postulated remdesivir may actually affect immunosuppression of cytokine storm syndrome, as opposed to directly acting antiviral effects.

Remdesivir was developed to treat Ebola virus infection, but demonstrated a broad antiviral spectrum against SARS-CoV, MERS-CoV, and various other RNA viruses (116). In Vero E6 cells infected with SARS-CoV-2, remdesivir potently blocked virus infection at high nanomolar concentrations with an $\mathrm{EC}_{50}$ value of $0.77 \mu \mathrm{M}$ demonstrating a low toxicity as the half-cytotoxic concentration was reported to be above $100 \mu \mathrm{M}(70)$. A separate study, however, estimated $\mathrm{EC}_{50}$ at $26.90 \mu \mathrm{M}(81)$. On the other hand, in $\mathrm{Caco} 2$ cells remdesivir inhibited SARS-CoV-2 cytopathogenic effects with an $\mathrm{EC}_{50}$ value of $0.23 \mu \mathrm{M}$ (70). The protective effect was increased 10 -fold by the addition of $8 \mu \mathrm{M}$ of omeprazole. Omeprazole alone has also demonstrated anti-SARS-CoV-2 protective effects, but at physiologically irrelevant concentrations $\left(\mathrm{EC}_{50}=34 \mu \mathrm{M}\right)$, substantially above those used in clinical practice. These results are presented in a yet to be peer-reviewed preprint (76).

Remdesivir was clinically tested in 175 patients in 2018 during the Ebola outbreak in the Democratic Republic of Congo by intravenous administration of $200 \mathrm{mg}$ on day 1 followed by daily maintenance doses of $100 \mathrm{mg}$ from day 2 and continuing for 9 to 13 days. In pediatric patients, the doses were adjusted based on body weight. The study revealed a favorable safety profile with higher mean levels of creatinine and aspartate aminotransferase but failed to achieve its primary endpoint (125).

A case report of the first COVID-19 patient identified in the U.S. presents their treatment with intravenous remdesivir on the seventh day of hospitalization and the improvement of their condition afterward (126). A similar case report described the remdesivir treatment of three hospitalized patients under compassionate use protocol. The patient described as number 6 was the same as the first case report. All three patients tolerated the remdesivir treatment, with transient gastrointestinal symptoms and a serum aminotransferase elevation (127). The administered doses were not mentioned in the article.

A randomized, double-blind, placebo-controlled clinical study (NCT04257656) on confirmed SARS-CoV-2 patients found that remdesivir ( $n=158$, vs. 79 placebo) intravenous administration of a $200 \mathrm{mg}$ loading dose on day 1 followed by $100 \mathrm{mg}$ daily as maintenance doses, up to a 10 days, produced no significant difference in time to clinical improvement. 
The 28-day mortality was similar between the remdesivir group (14\%) compared to placebo (13\%). However, remdesivir reduced the time to clinical improvement compared to placebo with a median of 18 vs. 23 days in the placebo group. The study reported no significant impact of remdesivir use on viral load measured on nasopharyngeal and oropharyngeal swabs, implying either no direct acting antiviral effect, or an unexpectedly long SARS-CoV-2 genome half-life (128). This result should be analyzed considering the long average time (10-11 days) from symptom onset to treatment start. We identified a number of other clinical trials that are trying to evaluate the antiviral activity of remdesivir in COVID-19 patients (NCT04252664, NCT04292899, NCT04292730, NCT04302766, NCT04323761, NCT04280705, NCT04321616, NCT04315948, NCT04314817, NCT04349410) using the same doses as NCT04257656 (56).

Favipiravir (6-fluoro-3-hydroxy-2-pyrazinecarboxamide), also known as T-705, was developed as a structural analog of 3-hydroxy-2-pyrazinecarboxamide (T-1105) compound identified in an in vitro anti-influenza virus activity drug screening (129). Favipiravir is a prodrug that is activated by cellular enzyme phosphoribosylation to favipiravir-ribofuranosyl-5'-triphosphate (favipiravir-RTP) (130). It is reported to selectively and potently inhibit the RNA-dependent RNA polymerase of a broad range of RNA viruses: influenza viruses, arenaviruses, bunyaviruses, noroviruses, flaviviruses and filoviruses (131). Favipiravir-RTP functions as a guanosine and adenosine analog, its antiviral activity being significantly inhibited by purine nucleotides and nucleosides, but not by pyrimidine nucleotides in an MDCK cell model. Yet favipiravir and its ribofuranosyl-5'-monophosphate showed no significant inhibitory effect on influenza virus RNA polymerase $(100 \mu \mathrm{M})$. Favipiravir has a similar structure and also a related antiviral spectrum as ribavirin increasing the lethal mutations in the viral genome; this activity raises concerns about teratogen risk potential (131). The pharmacokinetic profile was characterized in Japanese healthy volunteers to indicate a short half-life of 2 to $5.5 \mathrm{~h}$ and urinary excretion in the form of the inactive 5-hydroxy-metabolite (T-705M1) (132). Because of its teratogenicity and embryotoxicity risks, favipiravir was approved in Japan with strict regulations for use only in epidemics (133).

Similar to remdesivir, favipiravir blocked SARS-CoV-2 viral infection in Vero E6 cells, but at almost 80-fold higher concentrations, with a calculated $\mathrm{EC}_{50}$ value of $61.88 \mu \mathrm{M}(70)$. The results of an open-label comparative controlled study of patients with COVID-19 (ChiCTR2000029600) indicated that patients $(\mathrm{n}=35)$ receiving favipiravir $(1,600 \mathrm{mg} \times 2$, day 1 and $600 \mathrm{mg}$ x 2, days 2-14) had faster viral clearance and better chest imaging changes than those $(n=45)$ treated for 14 days with lopinavir (400 mg x 2) and ritonavir (100 mg x 2). Both groups also received aerosol inhalation of 5 million $U$ IFN- $\alpha$ twice daily (134). Several clinical trials are registered to test favipiravir in COVID-19 patients (NCT04358549, NCT04346628, NCT04310228,NCT04349241,NCT04336904,NCT04319900, NCT04359615, NCT04333589, NCT04303299, NCT04351295, NCT04356495, NCT04345419) administered orally at a loading dose of 3,200 up to $3,600 \mathrm{mg}(1,600-1,800 \mathrm{mg}$ at $12 \mathrm{~h})$ on day-1, followed by 1,200 to $1,800 \mathrm{mg}$ maintenance dose (600-800 $\mathrm{mg}$ at $12 \mathrm{~h}$ ) on days 2-10 (56).
Galidesivir, known also as BCX4430, is an adenosine $\mathrm{C}$-nucleoside analog similar to remdesivir, but has a nitrogen replacing the oxygen in the ribose ring. It is converted in the cell to the corresponding triphosphate nucleotide and after the pyrophosphate's cleavage to galidesivir monophosphate is incorporated into nascent viral RNA, blocking viral RNA-dependent RNA polymerase chain extension $(135,136)$. It was reported to be active against a wide range of viruses in cell and animal models (137). However, in a HeLa cell model of SARS-CoV infection, galidesivir had an $\mathrm{EC}_{50}$ value of $57.7 \mu \mathrm{M}$ (135). Considering the high similarity of nsp12 in SARS-CoV-2 and SARS-CoV (12), it was evaluated in Vero E6 cells against SARS-CoV-2, but the inhibition of viral replication was low at $100 \mu \mathrm{M}(81)$. Nevertheless, a clinical placebo-controlled, randomized study (NCT03891420) will test galidesivir administered intravenously at $12 \mathrm{~h}$ intervals for 7 days in COVID-19 patients (56).

A ribonucleoside derivative, $\beta$-D-N4-hydroxycytidine (known also as NHC or EIDD-1931), was reported to demonstrate potent inhibitory effects on MERS-CoV,SARS-CoV, and SARS-CoV-2 in Calu-3 and human airway epithelial (HAE) cells. Encouragingly, NHC inhibited SARS-CoV-2 infection in Vero E6 cells with $\mathrm{EC}_{50}$ values of $0.3 \mu \mathrm{M}$ and a value of $0.08 \mu \mathrm{M}$ in Calu-3 cells. The isopropyl ester of the prodrug NHC, EIDD-2801, was evaluated in C57BL/6 mice infected with a murine adapted SARS-CoV to reduce significantly the viral titer and associated infection symptoms when administered in doses of $500 \mathrm{mg} / \mathrm{kg}$. The antiviral mechanism of action proposes the inhibition of RdRp, with the effect of NHC being only slightly affected by ExoN proofreading activity $(138,139)$. Despite the potent antiviral profile of EIDD-2801 and its advantage of oral administration development for COVID, use is hindered by the lack of any clinical data.

Ribavirin (1- $\beta$-D-ribofuranosyl-1,2,4-triazole-3-carbox amide) is a broad-spectrum antiviral agent clinically used primarily for treating hepatitis $\mathrm{C}$. The antiviral mechanism is complex, the most important effects being the inhibition of human cells inosine monophosphate dehydrogenase (IMPDH) by the monophosphate derivative of the drug, and the incorporation of ribavirin 5'-triphosphate in the nascent viral genome by $\operatorname{RdRp}(25)$. Both ribavirin and favipiravir act as guanine analogs due to their carboxamide group that attaches to cytosine by hydrogen bonds (137).

In cell models of SARS-CoV infection ribavirin had a limited effect on viral replication (110). Similarly high concentrations are needed to block SARS-CoV-2 viral infection in Vero E6 cells $\left(\mathrm{EC}_{50}=109.5 \mu \mathrm{M}\right)(70)$ limiting clinical potential against COVID-19. The resistance of SARS-CoV and SARS-CoV-2 to ribavirin is produced by ExoN's proofreading activity during virus replication (119).

A systematic review of the therapies tested in the SARS-CoV outbreak of 2002-2003 found that among the 20 studies on ribavirin, results were inconclusive, with no discernible clinical differences to other treatments. The review highlights various toxic effects presented by several studies, the most frequent being hemolytic anemia and liver dysfunction (140). The high doses needed to reduce the viral replication highlight important toxic effects limiting the therapeutic potential of ribavirin treatments in COVID-19 cases. Despite these reservations, an open-label, non-randomized, clinical trial (NCT04356677) is 
programmed to test aerosolised administration of ribavirin twice daily for up to 6 days at $50 \mathrm{mg} / \mathrm{ml}$ or $100 \mathrm{mg} / \mathrm{ml}$ concentrations (56). A combination of lopinavir (400 mg), ritonavir (100 mg), ribavirin (400 mg), and IFN- $\beta$ lb (0.25 mg) is additionally under evaluation (NCT04276688) (56).

Targeting cellular signaling pathways. Viruses highjack host cell-signaling pathways, redirecting cellular processes in favor of their survival and replication, interfering with normal cell metabolism, survival, by interrupting transcription and replication (141). There are complex and not completely understood mechanisms of viral interference with cell signaling pathways. In the case of SARS-CoV-2, precise information is scarce and amplified by the large number of proteins of unknown function encoded in the virus genome, but research on new potential therapies can successfully use knowledge gained on the related SARS-CoV and MERS-CoV outbreak pathogens.

In cells infected with MERS-CoV perturbation of several regulatory kinases was detected, such as the increased phosphorylation of Aktl and mTOR, modifications that have been linked to a decrease in autophagy (142). Thus, the virus is believed to block autophagy through a complex mechanism dependent on viral nsp6 that involves phosphorylation of S-phase kinase-associated protein 2 (SPK2) by a complex involving FK506-binding protein 51 (FKBP51), PH domain leucine-rich repeat-containing protein phosphatases (PHLPP), Akt, and Beclin1 (BECN1). The activated SPK2 promotes the ubiquitination of BECN1 leading to its proteasomal degradation and inhibition of autophagy (103). A yet to be peer-reviewed report has proposed that SARS-CoV-2 infection may strongly reduce autophagic flux in experimental models of human bronchial epithelial cells NCI-H1299 and VeroFM cells (143). The analysis of Vero E6 cells infected with SARS-CoV revealed higher levels of Akt phosphorylated at serine 473 (S473) residue, but not at threonine 308 (T308) (144). The anti-apoptotic effect of Akt depends on both S473 and T308 phosphorylation (145) explaining low anti-apoptotic response to SARS-CoV infection (144). These observations highlight the potential of targeting SKP2 or the $\mathrm{PI} 3 \mathrm{~K} / \mathrm{AK}$ T/mTOR pathway.

MK-2206 is a selective and highly potent inhibitor of all three Akt isoforms, currently under clinical evaluation against various oncologic diseases (145). It reduced SARS-CoV-2 proliferation in VeroFM cells with a noteworthy $\mathrm{EC}_{50}$ value of $0.09 \mu \mathrm{M}$ measured after $24 \mathrm{~h}$ in plaque-forming units (143). This antiviral potential of MK-2206 expands upon the previously reported activity on influenza $\mathrm{pH} 1 \mathrm{~N} 1$ at $\mathrm{EC}_{50}$ values in the micromolar range (146).

Several protein kinase inhibitors targeting the ERK/MAPK and PI3K/AKT/mTOR signaling pathways were tested in Huh7 cells infected with MERS-CoV. Pretreatment with $10 \mu \mathrm{M}$ sirolimus (also known as rapamycin), an inhibitor of mTOR, reduced viral infection by a mediocre $61 \%$, while postinfection treatment effected a comparable $57 \%$ reduction. Everolimus, a 2-hydroxyethyl derivative of sirolimus, had similar inhibitory effects at $10 \mu \mathrm{M}$ (56\% reduction in pre-treated cells and $59 \%$ in postinfection treatment) (147). Surprisingly, the treatment of VeroFM cells with $0.3 \mu \mathrm{M}$ sirolimus increased the SARS-CoV-2 infection (143). Presently, a clinical trial (NCT04341675) is scheduled to assess sirolimus adminis- tered as $6 \mathrm{mg}$ on day 1 , followed by $2 \mathrm{mg}$ daily for the next 13 days (56). Metformin could be another repurposed drug for COVID-19 based on its autophagy induction by activation of AMP-activated protein kinase (AMPK) and inhibition of mTOR $(148,149)$.

Niclosamide is an oral antihelminthic drug used to treat a large array of parasitic infections being included on the WHO list of essential medicines (150). In a screening of marketed drugs it was identified to protect Vero E6 cells from the cytopathic effects of SARS-CoV (151). Niclosamide inhibited SARS-CoV replication in Vero E6 cells with a corresponding $\mathrm{EC}_{50}$ value under $0.1 \mu \mathrm{M}$, as measured by spike protein quantification (152). A yet not peer-reviewed preprint presents the SARS-CoV-2 growth inhibition of niclosamide with an $\mathrm{EC}_{50}$ value of $0.17 \mu \mathrm{M}$. The authors proposed a mechanism of action that implicates the inhibition of SPK2 (143). SPK2 inhibitors reverse the reduction of BECN1 levels produced by SARS-COV-2 in host cells and enhance autophagy, inhibiting the viral replication $(142,143)$. Another possible mechanism could be niclosamide's protonophore effect resulting in endosomal $\mathrm{pH}$ neutralization preventing acid-dependent virus replication (153). The maximum plasma concentration after $500 \mathrm{mg}$ x 3/day oral administration of niclosamide ranged from 35.7 to $182 \mathrm{ng} / \mathrm{ml}$, equivalent to $0.1-0.55 \mu \mathrm{M}$ (154). The results showed poor oral bioavailability that could hinder immediate clinical utility against COVID-19. The clinical trial NCT04372082 will evaluate niclosamide $500 \mathrm{mg}$ x 4/day (day 1 ) followed by $500 \mathrm{mg}$ x 2 /day (days 2-10) in combination with diltiazem $60 \mathrm{mg}$ x 3/day (days 1-10) (56). The use of diltiazem is supported by host-targeted antiviral effects demonstrated in influenza mouse models (155).

Nitazoxanide, known as 2-(acetyloxy)-N-(5-nitro-2-thiazolyl)benzamide, is a structural analog of niclosamide. Nitazoxanide is an antiprotozoal agent with proven broad-spectrum antiviral properties. It is a prodrug activated to its desacetyl derivative, tizoxanide, by hydrolysis. Both nitazoxanide and tizoxanide inhibited MERS-CoV replication in LLC-MK2 cells with mediocre $\mathrm{EC}_{50}$ values of $2.99 \mu \mathrm{M}(0.92 \mu \mathrm{g} / \mathrm{ml})$ and $3.13 \mu \mathrm{M}(0.83 \mu \mathrm{g} / \mathrm{ml})$, respectively (156). Nitazoxanide displayed similar effects on SARS-CoV-2 cultured in Vero E6 cells with an $\mathrm{EC}_{50}=2.12 \mu \mathrm{M}$ (70). The antiviral mechanism is possibly the same as niclosamide, as observed in RAW264.7 cells treated with tizoxanide. Tizoxanide increased BECN1 expression, inhibited Akt and mTOR, and promoted the formation of autophagy vacuoles (157). A placebo-controlled study (NCT04343248) is scheduled to evaluate nitazoxanide (300 mg x 2/day) as post-exposure prophylaxis for COVID-19 elderly patients, and a related study (NCT04359680) is focused on healthcare workers. Other clinical studies will test nitazoxanide in combination with hydroxychloroquine or with ivermectin (56).

Valinomycin is a toxic natural dodecadepsipeptide that also inhibits SPK2 and blocked SARS-CoV replication in Vero E6 cells $\left(\mathrm{EC}_{50}=1.63 \mu \mathrm{M}\right)(152)$.

Antiviral mechanisms. Umifenovir (also known as arbidol) is a broad-spectrum antiviral agent targeting both DNA and RNA, and both enveloped and non-enveloped viruses, currently used clinically for the prophylaxis and treatment of influenza in Russia and China. The antiviral mechanism is not known 
and is hypothesized to be directly virucidal coupled with host-targeting effects $(158,159)$, i.e., potentially polypharmacological in nature. In a retrospective study on COVID-19 patients, 16 people received umifenovir $200 \mathrm{mg}$ x 3/day, and 34 patients were treated with the lopinavir $(400 \mathrm{mg})$ /ritonavir $(100 \mathrm{mg})$ combination. The umifenovir group had a shorter duration of positive SARS-CoV-2 RT-PCR tests, suggesting that umifenovir monotherapy was more effective than lopinavir/ritonavir in reducing viral load in COVID-19 patients (160). Separately, a retrospective cohort study analyzed 16 patients who received umifenovir and lopinavir/ritonavir versus 17 patients that received lopinavir/ritonavir and found an apparent favorable clinical response in the former group (161). In a retrospective study on 45 patients treated with $200 \mathrm{mg}$ umifenovir three times a day for 5 days in 8 patients and 7 up to $10 \mathrm{mg}$ in the other 37 patients, no severe side effects were observed. The median time from admission to the first negative test and hospitalization time was longer compared to the control group, indicating that umifenovir alone may not accelerate SARS-CoV-2 clearance (162).

The antiviral effect of umifenovir was only recently investigated on Vero E6 infected with SARS-CoV-2. Umifenovir treatment reduced the viral cytopathic effects with an $\mathrm{EC}_{50}$ value of $4.11 \mu \mathrm{M}$, but with a relatively low selectivity $(\mathrm{SI}=7.73)$. After a single oral dose of $800 \mathrm{mg}$, the maximal plasma concentration in man was ascertained at $\sim 4.1 \mu \mathrm{M}$. These data suggest that the doses of $200 \mathrm{mg}$ three times a day are too low for a physiological relevant antiviral effect (163).

Ivermectin represents a mixture of two semisynthetic avermectins and belongs to the chemical family of 16-membered macrocyclic lactones. It is used for over three decades to treat various parasitic infections being included on the WHO list of essential medicines (164). The antiviral effects of ivermectin on various RNA viruses like influenza, Dengue virus, or West Nile Virus prompted its evaluation against SARS-CoV-2. Vero/hSLAM cells were infected with SARS-CoV-2 and treated with $5 \mu \mathrm{M}$ ivermectin. After $24 \mathrm{~h}$ the viral RNA was reduced by $93 \%$ in the supernatant and by $99.8 \%$ in the cells. After $48 \mathrm{~h}$ of treatment, the viral RNA decrease was close to $5,000 \mathrm{x}$ (165). The $\mathrm{EC}_{50}$ value was determined to be $\sim 2 \mu \mathrm{M}$ and the hypothesized mechanism of action implicated blockade of viral protein transport in the nucleus by dissociation of the host importin $\alpha / \beta 1$ heterodimer $(165,166)$ - mechanism not in line with the exclusively cytosolic life cycle of SARS-CoV-2. Ivermectin is most frequently used for onchocerciasis, strongyloidiasis, and enterobiasis in doses of 150 to $200 \mu \mathrm{g} / \mathrm{kg}$, and up to $400 \mu \mathrm{g} / \mathrm{kg}$ in patients with lymphatic filariasis (167). A clinical study (NCT04343092) is programmed to test ivermectin in COVID-19 patients as a single dose of $200 \mu \mathrm{g} / \mathrm{kg}$ in combination with daily doses of hydroxychloroquine (400 mg) and azithromycin $(500 \mathrm{mg})$. Two other clinical trials are registered to test ivermectin, one in combination with chloroquine (NCT04351347), and another (NCT04360356) in association with nitazoxanide (56).

Emetine is a natural tetrahydroisoquinoline alkaloid from ipecac species with potent inhibitory effects on the replication of a broad range of DNA and RNA viruses. Emetine displayed potent anti-MERS-CoV activity in Vero E6 cells, with an $\mathrm{EC}_{50}=0.34 \mu \mathrm{M}\left(\right.$ after $72 \mathrm{~h}$ ) and $\mathrm{SI}=9.06$ (168). The $\mathrm{EC}_{50}$ value against SARS-CoV-2 was evaluated as $0.5 \mu \mathrm{M}$ after $48 \mathrm{~h}$, a concentration almost 3-fold higher than emetine's therapeutic plasma concentration (81), hindering its clinical use in COVID-19 patients. Lycorine is a structurally related alkaloid found in Amaryllidaceae species, with potent anti-MERS-CoV effects $\left(E_{50}=1.63 \mu \mathrm{M}\right)$, but with therapeutic doses that exceed the toxic ones (168). Homoharringtonine is an alkaloid approved as a prodrug derivative, omacetaxine mepesuccinate, for chronic myeloid leukemia treatment. It yields potent and broad anti-RNA virus effects by reducing the phosphorylation level of the eukaryotic initiation factor 4E (eIF4E) (169). Homoharringtonine reduced SARS-CoV-2 viral load in Vero E6 cells with an $\mathrm{EC}_{50}$ value of $2.10 \mu \mathrm{M}$ (81). Zotatifin (eFT226) is an inhibitor of eukaryotic initiation factor 4A (eIF4A) under evaluation for advanced solid tumor malignancies and produced strong antiviral effects in Vero E6 cell models of SARS-CoV-2 viral infection (170).

A number of antiviral compounds were evaluated against SARS-CoV-2 with disappointing results. Oseltamivir, a neuraminidase inhibitor frequently used for influenza patients showed no significant antiviral effects at concentrations under $100 \mu \mathrm{M}$ in Vero E6 cell models. The same result was obtained for baloxavir acid, the active form of the baloxavir marboxil prodrug. In influenza viruses it has been reported to block viral RNA synthesis by inhibiting endonuclease activity (81). Other influenza neuraminidase inhibitors such as laninamivir, peramivir, and zanamivir had no result on the cytopathic effects of SARS-CoV-2 activity even at high concentrations (163).

Modulation of the immune defense. The response induced by viruses in the human host is a combination of innate and acquired immunity that unfolds in a sequence, well known in many aspects, but considerably nuanced between distinct insults. Thus, foreign matter recognition initiates lympocyte recruitment, to progresses into a resolution phase that normally seeks to return to homeostasis (171). The inflammatory response to SARS-CoV-2 generally begins when pathogen-associated molecular patterns (PAMP), such as viral RNA, and damage-associated molecular patterns (DAMPs), including ATP, DNA, and ASC oligomers, are recognized by cell surface and cytosolic PAMP recognition receptors (PRRs). The ensuing secretion of pro-inflammatory cytokines and chemokines, such as IL-6, IFN- $\gamma$, monocyte chemoattractant protein 1 (MCP1), and CXCL10, attracts monocytes and $\mathrm{T}$ lymphocytes, but, unusually, not neutrophils, to the infected site (172). The impact of cytokines is generally increased in obesity, which is associated with higher baseline inflammatory status, explaining the higher risk of complications for obese patients infected with SARS-CoV-2 (173).

The cytokine IL- 6 is one of the most important acute inflammatory mediators secreted early during an infection, along with IL-1 and TNF- $\alpha$ (174). Immunosuppressants targeting these molecules are needed to reverse the rampant immune activation observed in late stage, severe forms of COVID-19 (175). A comprehensive list of immunosuppressive therapies aimed at limiting immune-mediated damage produced by SARS-CoV-2 infection are presented in Table I.

IL-6 is produced in response to acute inflammation, primarily in response to stimulation by TNF- $\alpha$, lipopolysaccharides, and IL-1 (179). The cellular sensor for IL-5 is the surface-expressed IL-6 receptor (IL-6R; classical signaling 


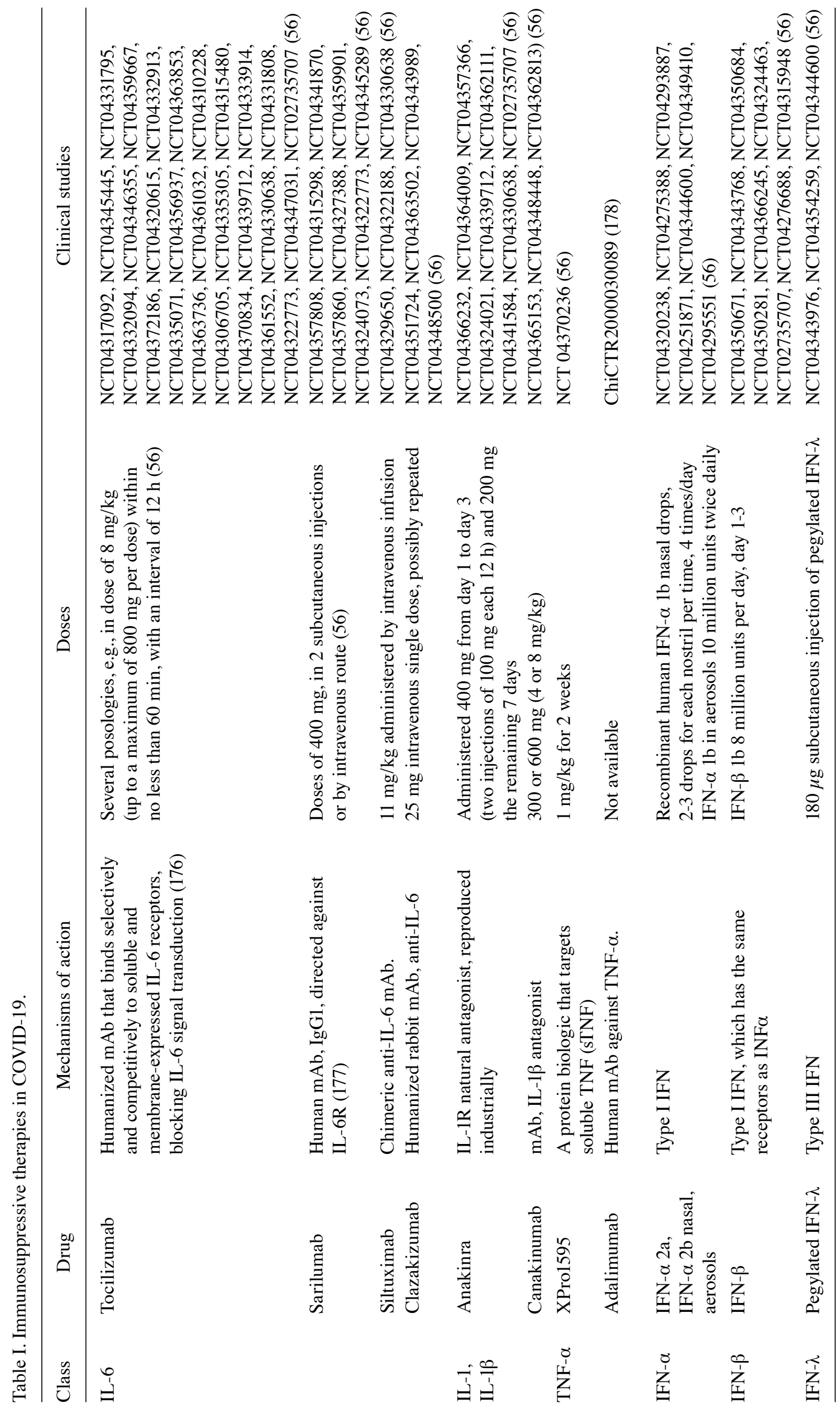


pathway) or through soluble IL-6R (trans-signaling pathway) (180). The first pathway could be anti-inflammatory as IL-6 plays a pivotal role in the polarization of immune responses toward Th1, inhibiting the production of IFN- $\gamma$ by CD $4 \mathrm{~T}$ cells, and by consequence CD8 T cell activation (174). The signaling through soluble IL-6R has different consequences. The complex of IL- 6 and soluble IL-6R can bind to a membrane structure named gp130 on cells that do not express IL-6R, initiating what appear to be pro-infammatory cascades in cells otherwise non-responsive to IL-6 (181).

Several studies report elevations in IL-6 levels in patients with COVID-19 $(45,182,183)$. A retrospective study on 191 hospitalized COVID-19 patients from the Wuhan region found higher IL-6 levels in the non-survivor group, compared to survivors (184). A meta-analysis study reported a 2.9 -fold higher level of IL-6 in difficult COVID-19 cases in contrast to non-complicated ones (185). IL-6 has also an essential role in the pathophysiology of rheumatoid arthritis being a validated target for rheumatoid arthritis therapies (186), driving drug repurposing studies for the IL- 6 mediated-management of COVID-19.

Tocilizumab is a humanized monoclonal antibody $(\mathrm{mAb})$ directed against the IL- 6 receptor used as an effective therapeutic agent for rheumatoid arthritis patients who do not respond to methotrexate (176). A retrospective analysis of published studies involving the use of tocilizumab in patients with COVID-19 highlighted the importance of close patient monitoring for neutropenia, thrombocytopenia, and elevated liver enzymes (187). A pilot prospective open, single-arm study evaluated tocilizumab in 63 hospitalized patients with severe COVID-19 to report improved respiratory and laboratory parameters (188). Sarilumab is a fully humanised monoclonal antibody that specifically binds to both soluble and membrane-bound IL-6 receptors (189). Siltuximab and clazakizumab are antibodies targeting IL- 6 that are under clinical evaluation for severe lung disease associated with SARS-CoV-2 infection (190).

IL-1 receptor signaling is implicated early in infection, preceeding IL-6 expression. However, it is also responsible for acute tissue inflammatory damage. In mice, the cytokine storm is associated with elevated levels of IL-1 (174), and a potentiation of TNF- $\alpha$ (191). Using anakinra, the synthetic form of natural IL-1 receptor antagonist, it has been shown in mice that IL-1 signalling blockade could be a potential treatment of influenza infections, arresting airway neutrophilia early in the infection cycle, but also during the peak of viral replication (192).

TNF- $\alpha$ is a key component of the cytokine response and is implicated in COVID-19 severity, as it is found at elevated levels among severe cases (45). There is considerable clinical experience globally with several antibodies targeting TNF- $\alpha$ in clinic against severe cases of autoimmune inflammatory disease, such as rheumatoid arthritis, Crohn's disease, ankylosing spondylitis, or psoriasis (193). The idea of repurposing anti-TNF- $\alpha$ immunotherapies for the management of COVID-19 is supported by preclinical studies on influenza mouse models (193). Adalimumab, a fully humanised monoclonal antibody, is under evaluation in COVID-19 patients (185).
Activation of the nicotinic receptor $\alpha 7$ on immune cells also reduces the levels of IL-6 and TNF- $\alpha$ (171). Based on this effect, it has been hypothesized that nicotine, a cholinergic agonist, could have protective effects in COVID-19 patients (194). However, it is unlikely that nicotine can be used clinically due to its addictive effects and lack of specificity (171). Rather, a review based on the available literature on the impact of smoking on COVID-19 identified a number of studies highlighting a history of smoking as a prognostic factor for severe outcomes, while a meta-analysis study found no significant correlation between smoking and the severity of COVID-19 disease (195).

The interferon family, whose expression is induced directly and indirectly following viral PAMP recognition, is critical in directing innate and adaptive immunity direction. Thus, the interferon cascade induces multiple host antiviral factors or immunomodulators. Activation of either of the two members of the IFN- $\alpha$ receptor (IFNAR) family initiates cytosolic signalling cascades culminating in the transcriptional activation of numerous IFN-stimulated genes (ISGs). The protein products of these transcripts exhibit antiviral principally through inhibition of viral replication. Furthermore, type I IFNs enhance natural killer cell activity and antiviral $\mathrm{T}$ cell responses, which are central to antiviral defence (196).

A comprehensive evaluation of the therapies tested in the SARS-CoV outbreak found two studies reporting IFN- $\alpha$ therapies in combination with steroids and/or ribavirin, without a significant difference in the clinical outcome when compared to other therapies used (140). A preprint report suggests a higher susceptibility of SARS-CoV-2 to type I IFN treatment compared to SARS-CoV (197). These results were reaffirmed on Vero cells treated with IFN- $\alpha$ or IFN- $\beta$, returning $\mathrm{EC}_{50}$ values for SARS-CoV-2 at $1.35 \mathrm{IU} / \mathrm{ml}$ for IFN- $\alpha$, and $0.76 \mathrm{IU} / \mathrm{ml}$ for IFN- $\beta$. In contrast, SARS-CoV $\mathrm{EC}_{50}$ values were reported to range between 95 to $105 \mathrm{IU} / \mathrm{ml}$ depending on the viral strains used (198).

Several immunosuppressants are also being examined as potential solutions for severe COVID-19, with the highest interest being in drugs such as methotrexate, JAK inhibitors (ruxolitinib, baricitinib, tofacitinib, imatinib), colchicine, thalidomide, and lenalidomide. Methotrexate-loaded nanoparticles administered intravenously at $20 \mathrm{mg}$, once per week (total of 4 doses), is under evaluation in one trial (NCT04352465) (56). Imatinib, an Abl kinase inhibitor and to a lesser extent, a JAK/STAT inhibitor, is used as an experimental drug in elderly COVID-19 patients in out-of-hospital settings at doses of $400 \mathrm{mg} /$ day, 7 days (NCT04346147, NCT04357613, NCT04356495) (56). Colchicine presents long-established anti-inflammatory properties and neutrophil inhibitory effects and is currently under evaluation in COVID-19 patients (NCT04322682, NCT04322565, NCT04328480, NCT04326790, NCT04350320) $(184,199)$. Thalidomide plus low doses of glucocorticoids, umifenovir, and IFN- $\alpha$ aerosols have been used in NCT04273581 and NCT04273529. Lenalidomide, a structural derivative of thalidomide, is currently under evaluation as $4 \mathrm{mg} / \mathrm{day}$ on days 1, 3 and 5, in less severe cases of COVID-19 associated with low-molecular weight heparin (NCT04361643) (56). Eculizumab is a recombinant humanized monoclonal antibody that targets complement component 5 and is under clinical 
study in 900-1200 $\mathrm{mg}$ doses administered intravenously (NCT04355494) (56).

Dietary supplements. Ascorbic acid or vitamin C is an established antioxidant and reactive oxygen species scavenger widely considered to alleviate or prevent infections (200). Vitamin C was proposed as a supportive treatment for COVID-19 and several clinical trials are registered to assess its effects. The clinical study NCT04323514 uses intravenous administration of $10 \mathrm{~g}$ of vitamin C, while study NCT04342728 uses $8 \mathrm{~g}$ of ascorbic acid divided into 2-3 doses/day alone or combined with $50 \mathrm{mg}$ of zinc gluconate, and the NCT04344184 study uses $100 \mathrm{mg} / \mathrm{kg}$ vitamin $\mathrm{C}$ intravenously administered every $8 \mathrm{~h}$ for up to $72 \mathrm{~h}$ (56). An article details a Chinese expert report on clinical improvement of 50 moderate to severe COVID-19 patients treated intravenously with 10-20 g/day (201). Vitamin D influences the immune response by modulating several immune pathways and its deficiency was correlated with increased risks of respiratory infections (202). The clinical study NCT04334005 will test administration of a single dose of 25,000 IU of vitamin D as supplement in addition to standard therapies, while in NCT04334005 vitamin D will be given orally as 50,000 IU once weekly for 2 weeks in combination with $81 \mathrm{mg}$ of acetylsalycilic acid (56). Zinc has anti-inflammatory effects moderating $\mathrm{T}$ cell functions that could limit excess cytokine production in COVID-19 patients (203). Selenium supplementation was shown to increase immunity and could be used in SARS-CoV-2 infections (204). The clinical study NCT04323228 is scheduled to test an oral supplement enriched in eicosapentaenoic acid, gamma-linolenic acid containing $18 \mu \mathrm{g}$ selenium and $5.7 \mathrm{mg}$ zinc (56).

Oligonucleotide and gene therapy-based approaches. With the precise mechanism of SARS-CoV-2 migration from respiratory epithelia onto distal ACE2-expressing organs remaining unclear, direct intervention at the RNA genome level of SARS-CoV-2 is also attracting research attention. However, efforts in this space, compared to the advanced nature of vaccine and small molecule intereventions, can only be characterized as speculative and preliminary.

The most clinically advanced drug classes in this space are short interfering RNA (siRNA) and ribonuclease $\mathrm{H}$ (RNaseH)-active oligonucleotide antisense therapeutics, modalities that have enjoyed serial regulatory approval successes and become commercially viable since 2016. Thus, first pass metabolism affords adequate passive liver uptake after systemic administration to tackle hereditary hepatic diseases [e.g., mipomersen (205)]. Similarly, intrathecal administration of antisense has proven an effective intervention against spinal muscular atrophy [nusinersen (206)] and ushered true n-of-1 medicine [milasen (207)]. Yet all clinical candidates evaluated between 2000-2011 for lung diseases of inflammatory or viral nature achieved ambiguous and inadequate outcomes, despite the apparent facility of topical dosing to the airways (208). This has been largely attributed to misconceptions around systemic bioavailability and topical cytosolic delivery potential, as rodent studies of oligonucleotide bioavailability following respiratory dosing (32) reflect allometrically scaled human pharmacokinetics even onto demonstrating effective hepatic and kidney targeting $(32,209)$. Does this preclude topical intervention to prevent ACE2 receptor docking of SARS-CoV-2? Unfortunately, even the single clinical stage antisense candidate AZD1419 targeting the cell surface TLR9 to improve time-to-loss of eosinophilic, moderate-to-severe asthma control, also reportedly failed to meet primary endpoints in the phase 2 a INCONTRO trial (NCT02898662) (56). Although clarity over respiratory TLR9 coverage by the adopted dosing regime remains undetermined, direct comparisons are ill-advised, thus focusing future intervention efforts in four areas.

At first instance, aptamer-mediated inhibition of ACE2 binding and TMPRSS2 activity, either solely or as a combination therapy, presents a rational means of intervention to prevent viral adhesion and cellular entry, similar to that proposed by small molecule inhibitors. Although cost of goods, chemistry, manufacturing and control requirements are significantly higher for this chemotherapeutic class vs small molecule drugs, rapid hit generation by modern aptamer development methods $(210,211)$ and established orthogonal aptamer optimization strategies can deliver clinical candidates compatible with scalable manufacturing pertinent to pandemic outbreaks, in timelines comparable or better than antibody biotherapeutics. Thus, in the event of complete failure across the vast number of repurposed medication trials described in this review, a second wave of aptamer-based treatments could be ready for subsequent clinical testing. Significantly, systemic access achieved through the lung (32) may afford distal tissue protection from SARS-CoV-2 infection.

The following approaches would involve the generation of antisense, siRNA chemo- and biotherapeutics (DNA Directed RNA interference mediators in the form of short hairpin RNA (shRNA) precursors), or CRISPR-CAS13 systems (212) that would seek to directly cleave the RNA genome of SARS-CoV-2. Cytosolic delivery challenges notwithstanding, the paucity of reports indicating multi-log suppression of viral replication by these chemotherapeutic classes irrespective of target RNA virus, and the diverse evidence of rapid viral evolutionary escape, combination therapy is likely to be necessary (213) to afford either protection, or treatment against SARS-CoV-2 by any such agents. In this respect, RNA-cleaving CRISPR-CAS13 systems suffer from macromolecular ribonucloprotein complex requirements that compound drug delivery challenges vs the relatively smaller molecular weight of oligonucleotides, that rely on host proteins to exert their mechanism of action.

Poignantly, the only modality proven to achieve cytosolic delivery in the lung are adeno-associated virus 6 biotherapeutics $(214,215)$ for the minigene treatment of cystic fibrosis (216). Although this drug class has yet to be attempted against viral respiratory diseases, the safety of AAV-mediated triple antiviral shRNA expression has been demonstrated in man even onto phase IIb against HCV (NCT01899092). Consequently, a brief anti-SARS-CoV-2 shRNA discovery and optimization campaign coupled to promoter optimization experiments (217) in physiologically relevant organoid models could yield a high confidence-in-safety and confidence-in-rationale candidate drug with the potential to suppress viral escape (218) if adequately tuned to express shRNAs in vivo without inter- 


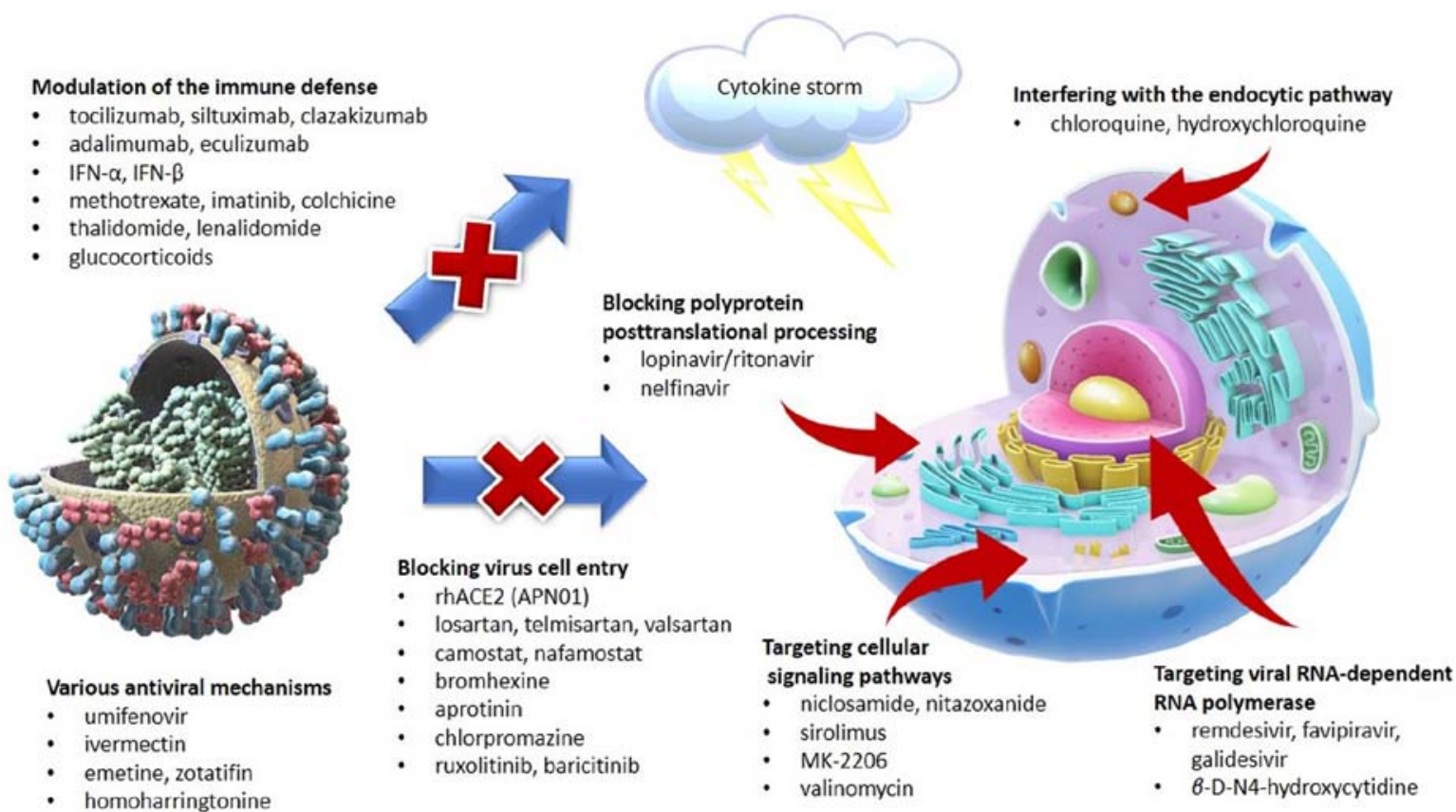

Figure 4. Overview of mechanistic pathways and molecular targets of major potential COVID-19 treatments.

rupting microRNA homeostasis. Significantly, the approach benefits from a 'fire and forget', single, inhaled administration that would mediate transgene expression within 3 days of dosing and for up to 6 months (217), or potentially longer. It is, therefore, proposed that such an intervention may compensate for broad-spectrum, short-term protection from SARS-CoV-2 infection in high risk populations in the event of failure to deliver protective vaccines, or vaccination ineligibility due underlying immunosuppression.

\section{Discussion}

Assembling this review was an exciting and laborious daunting task, considering the astonishing volume of research published and the urgency of finding effective, yet safe, therapeutical solutions for COVID-19. The high pressure on the research community leads both to very good studies and publications, but also hasty and poorly designed studies, biased conclusions, or unproven hypotheses, all mixed together. The research directions were heavily influenced by the evolution of the COVID-19 epidemic. At the early stages of the outbreak in China, patients received oseltamivir based on the erroneous diagnosis of influenza. Even if neuraminidase, the target of oseltamivir, was invalidated for COVID-19 treatments, several ongoing clinical trials still include oseltamivir as a comparison group (51).

Repurposing was also a rapid response solution based on the experience with SARS-CoV, MERS-CoV, or with other viruses. Many of the repurposed drugs undergoing clinical trials were not tested in cell models against SARS-CoV-2, raising questions about their real efficacy. Even so, the cell models can be misleading because most compounds have not been tested on human cells and because only $\mathrm{EC}_{50}$ values are reported without clear information on the dose-response curve. Several conditions such as different multiplicities of infection or time of exposure can dramatically influence the
$\mathrm{EC}_{50}$ values. There are several other concerns that are worth mentioning: the potential of a drug to reach the target tissue and how it would perform under complex, disease-altered conditions (Fig. 4).

Future research should focus on how the virus evades the immune response and try to better understand its interaction with the $\mathrm{T}$ and $\mathrm{B}$ cell responses, both in the humans and experimentally infected animals. The second goal should be to reveal and assess details of viral replication strategies and pathways, determining the relationship between sites of viral RNA replication and virus assembly, as well as the extent to which virus-host interactions are SARS-CoV-2 specific and organ-specific, using genomics and proteomics, as well as new reagents. A third future goal should be to translate new information about the structure and function of SARS-CoV-2 proteins into specific anti-virus therapies, particularly with respect to the SARS-CoV-2 proteins of unknown function. The next goal will be the understanding of viral pathogenesis, to design and develop effective live or attenuated safe vaccines. It is anticipated that, like other RNA viruses, subgenomic SARS-CoV-2 replicon systems adapted to lung, kidney, and even neuronal cell types will catalyse the understanding of SARS-CoV-2 biology.

\section{Acknowledgements}

Not applicable.

\section{Funding}

No funding was received.

\section{Availability of data and materials}

Data sharing is not applicable to this article, as no datasets were generated or analyzed during the current study. 


\section{Authors' contributions}

Conception: GMN, AT. Acquisition of data, design and writing: GM, HP, SAM, DP, GN, GNDI, DAS, TKN, ND, AT. All authors have read and approved the final manuscript.

\section{Ethics approval and consent to participate}

Not applicable.

\section{Patient consent for publication}

Not applicable.

\section{Competing interests}

SAM is the CSO and Founder of PulmoBioMed Ltd., a Northumbria University spin out company but had no personal interest in product promotion, or any influence in terms of the content of this article. DAS is the Editor-in-Chief for the journal, but had no personal involvement in the reviewing process, or any influence in terms of adjudicating on the final decision, for this article. The other authors declare that they have no competing interests.

\section{References}

1. Lai CC, Shih TP, Ko WC, Tang HJ and Hsueh PR: Severe acute respiratory syndrome coronavirus 2 (SARS-CoV-2) and coronavirus disease-2019 (COVID-19): The epidemic and the challenges. Int J Antimicrob Agents 55: 105924, 2020.

2. Fehr AR and Perlman S: Coronaviruses: An overview of their replication and pathogenesis. Methods Mol Biol 1282: 1-23, 2015.

3. Chen Y, Liu Q and Guo D: Emerging coronaviruses: Genome structure, replication, and pathogenesis. J Med Virol 92: 418-423, 2020.

4. Tsatsakis A, Petrakis D, Nikolouzakis TK, Docea AO, Calina D, Vinceti M, Goumenou M, Kostoff RN, Mamoulakis C, Aschner M and Hernández AF: COVID-19, an opportunity to reevaluate the correlation between long-term effects of anthropogenic pollutants on viral epidemic/pandemic events and prevalence. Food Chem Toxicol (In Press).

5. Goumenou M, Sarigiannis D, Tsatsakis A, Anesti O, Docea AO, Petrakis D, Tsoukalas D, Kostoff R, Rakitskii V, Spandidos DA, et al: COVID-19 in Northern Italy: An integrative overview of factors possibly influencing the sharp increase of the outbreak (Review). Mol Med Rep 22: 20-32, 2020

6. Xu Z, Shi L, Wang Y, Zhang J, Huang L, Zhang C, Liu S, Zhao P, Liu H, Zhu L, et al: Pathological findings of COVID-19 associated with acute respiratory distress syndrome. Lancet Respir Med 8: 420-422, 2020

7. Li X, Geng M, Peng Y, Meng L and Lu S: Molecular immune pathogenesis and diagnosis of COVID-19. J Pharm Anal 10: $102-108,2020$

8. Docea AO, Tsatsakis A, Albulescu D, Cristea O, Zlatian O, Vinceti M, Moschos SA, Tsoukalas D, Goumenou M, Drakoulis N, et al: A new threat from an old enemy: Re-emergence of coronavirus (Review). Int J Mol Med 45: 1631-1643, 2020.

9. Paules CI, Marston HD and Fauci AS: Coronavirus infections - more than just the common cold. JAMA 323: 707, 2020.

10. Lu R, Zhao X, Li J, Niu P, Yang B, Wu H, Wang W, Song H, Huang B, Zhu N, et al: Genomic characterisation and epidemiology of 2019 novel coronavirus: Implications for virus origins and receptor binding. Lancet 395: 565-574, 2020.

11. Zhou P, Yang XL, Wang XG, Hu B, Zhang L, Zhang W, Si HR, Zhu Y, Li B, Huang CL, et al: A pneumonia outbreak associated with a new coronavirus of probable bat origin. Nature 579 , $270-273,2020$
12. Wu A, Peng Y, Huang B, Ding X, Wang X, Niu P, Meng J, Zhu Z, Zhang Z, Wang J, et al: Genome composition and divergence of the Novel Coronavirus (2019-nCoV) originating in China. Cell Host Microbe 27: 325-328, 2020.

13. Knoops K, Kikkert M, Worm SH, Zevenhoven-Dobbe JC, van der Meer Y, Koster AJ, Mommaas AM and Snijder EJ: SARS-coronavirus replication is supported by a reticulovesicular network of modified endoplasmic reticulum. PLoS Biol 6: e226, 2008.

14. Alsaadi EA and Jones IM: Membrane binding proteins of coronaviruses. Future Virol 14: 275-286, 2019.

15. Robbins M, Judge A, Liang L, McClintock K, Yaworski E and MacLachlan I: 2'-O-methyl-modified RNAs act as TLR7 antagonists. Mol Ther 15: 1663-1669, 2007.

16. Kikkert M: Innate immune evasion by human respiratory RNA viruses. J Innate Immun 12: 4-20, 2020.

17. Gordon DE, Jang GM, Bouhaddou M, Xu J, Obernier K, White KM, O'Meara MJ, Rezelj VV, Guo JZ, Swaney DL, et al: A SARS-CoV-2 protein interaction map reveals targets for drug repurposing. Nature: https://doi.org/10.1038/s41586-0202286-9.

18. Wrapp D, Wang N, Corbett KS, Goldsmith JA, Hsieh CL, Abiona O, Graham BS and McLellan JS: Cryo-EM structure of the 2019-nCoV spike in the prefusion conformation. Science 367: 1260-1263, 2020.

19. To KF and Lo AWI: Exploring the pathogenesis of severe acute respiratory syndrome (SARS): The tissue distribution of the coronavirus (SARS-CoV) and its putative receptor, angiotensin-converting enzyme 2 (ACE2). J Pathol 203: 740-743, 2004.

20. Hamming I, Timens W, Bulthuis MLC, Lely AT, Navis G and van Goor H: Tissue distribution of ACE2 protein, the functional receptor for SARS coronavirus. A first step in understanding SARS pathogenesis. J Pathol 203: 631-637, 2004

21. Hoffmann M, Kleine-Weber H, Schroeder S, Krüger N, Herrler T, Erichsen S, Schiergens TS, Herrler G, Wu NH, Nitsche A, et al: SARS-CoV-2 cell entry depends on ACE2 and TMPRSS2 and is blocked by a clinically proven protease inhibitor. Cell 181: 271-280.e8, 2020.

22. Sawicki SG, Sawicki DL and Siddell SG: A contemporary view of coronavirus transcription. J Virol 81: 20-29, 2007.

23. Rabi FA, Al Zoubi MS, Kasasbeh GA, Salameh DM and Al-Nasser AD: Sars-cov-2 and coronavirus disease 2019: What we know so far. Pathogens 9: E231, 2020.

24. Gribble J, Pruijssers AJ, Agostini ML, Anderson-Daniels J, Chappell JD, Lu X, Stevens LJ, Routh AL and Denison MR: The coronavirus proofreading exoribonuclease mediates extensive viral recombination. bioRxiv: https://doi. org/10.1101/2020.04.23.057786.

25. Ferron F, Subissi L, Silveira De Morais AT, Le NTT, Sevajol M, Gluais L, Decroly E, Vonrhein C, Bricogne G, Canard B, et al: Structural and molecular basis of mismatch correction and ribavirin excision from coronavirus RNA. Proc Natl Acad Sci USA 115: E162-E171, 2018.

26. Forster P, Forster L, Renfrew C and Forster M: Phylogenetic network analysis of SARS-CoV-2 genomes. Proc Natl Acad Sci USA 117: 9241-9243, 2020.

27. Tang X, Wu C, Li X, Song Y, Yao X, Wu X, Duan Y, Zhang H, Wang Y, Qian Z, et al: On the origin and continuing evolution of SARS-CoV-2. Natl Sci Rev: nwaa036, 2020.

28. Korber B, Fischer W, Gnanakaran SG, Yoon H, Theiler J, Abfalterer W, Foley B, Giorgi EE, Bhattacharya T, Parker MD, et al: Spike mutation pipeline reveals the emergence of a more transmissible form of SARS-CoV-2. bioRxiv: https:// doi.org/10.1101/2020.04.29.069054.

29. van Dorp L, Acman M, Richard D, Shaw LP, Ford CE, Ormond L, Owen CJ, Pang J, Tan CCS, Boshier FAT, et al: Emergence of genomic diversity and recurrent mutations in SARS-CoV-2. Infect Genet Evol: May 5, 2020 (Epub ahead of print).

30. Bilinska K, Jakubowska P, Von Bartheld CS and Butowt R: Expression of the SARS-CoV-2 entry proteins, ACE2 and TMPRSS2, in cells of the olfactory epithelium: identification of cell types and trends with age. ACS Chem Neurosci: May 7, 2020 (Epub ahead of print).

31. Ziegler CGK, Allon SJ, Nyquist SK, Mbano IM, Miao VN, Tzouanas CN, Cao Y, Yousif AS, Bals J and Hauser BM: SARS-CoV-2 receptor ACE2 is an interferon-stimulated gene in human airway epithelial cells and is detected in specific cell subsets across tissues. Cell: https://doi.org/10.1016/j.cell.2020.04.035. 
32. Moschos SA, Frick M, Taylor B, Turnpenny P, Graves $\mathrm{H}$ Spink KG, Brady K, Lamb D, Collins D, Rockel TD, et al: Uptake, efficacy, and systemic distribution of naked, inhaled short interfering RNA (siRNA) and locked nucleic acid (LNA) antisense. Mol Ther 19: 2163-2168, 2011.

33. Di Pasquale $G$ and Chiorini JA: AAV transcytosis through barrier epithelia and endothelium. Mol Ther 13: 506-516, 2006.

34. Lin L, Lu L, Cao W and Li T: Hypothesis for potential pathogenesis of SARS-CoV-2 infection - a review of immune changes in patients with viral pneumonia. Emerg Microbes Infect 9: 727-732, 2020.

35. Wu Y, Guo C, Tang L, Hong Z, Zhou J, Dong X, Yin H, Xiao Q, Tang Y, Qu X, et al: Prolonged presence of SARS-CoV-2 viral RNA in faecal samples. Lancet Gastroenterol Hepatol 5: 434-435, 2020

36. Xiao F, Tang M, Zheng X, Liu Y, Li X and Shan H: Evidence for gastrointestinal infection of SARS-CoV-2. Gastroenterology 158: 1831-1833.e3, 2020.

37. Song C, Wang Y,Li W, Hu B, Chen G, Xia P, Wang W, Li C, Hu Z Yang X, et al: Detection of 2019 novel coronavirus in semen and testicular biopsy specimen of COVID-19 patients. medRxiv: doi: https://doi.org/10.1101/2020.03.31.20042333.

38. Chen Y and Li L: SARS-CoV-2: Virus dynamics and host response. Lancet Infect Dis 20: 515-516, 2020.

39. Yi Y, Lagniton PNP, Ye S, Li E and Xu RH: COVID-19: What has been learned and to be learned about the novel coronavirus disease. Int J Biol Sci 16: 1753-1766, 2020.

40. Shi Y, Wang Y, Shao C, Huang J, Gan J, Huang X, Bucci E, Piacentini M, Ippolito G and Melino G: COVID-19 infection: The perspectives on immune responses. Cell Death Differ 27: 1451-1454, 2020.

41. Guo L, Ren L, Yang S, Xiao M, Chang D, Yang F, Dela Cruz CS, Wang Y, Wu C, Xiao Y, et al: Profiling early humoral response to diagnose novel Coronavirus Disease (COVID-19). Clin Infect Dis ciaa310, 2020

42. To KKW, Tsang OTY, Leung WS, Tam AR, Wu TC, Lung DC, Yip CC, Cai JP, Chan JM, Chik TS, et al: Temporal profiles of viral load in posterior oropharyngeal saliva samples and serum antibody responses during infection by SARS-CoV-2: An observational cohort study. Lancet Infect Dis 20: 565-574, 2020

43. Cao Z, Liu L, Du L, Zhang C, Jiang S, Li T and He Y: Potent and persistent antibody responses against the receptor-binding domain of SARS-CoV spike protein in recovered patients. Virol J 7: 299, 2010

44. Calina D, Docea AO, Petrakis D, Egorov AM, Ishmukhametov AA, Gabibov AG, Shtilman MI, Kostoff R, Carvalho F, Vinceti M, et al: Towards effective COVID-19 vaccines: Updates, perspectives and challenges (Review). Int J Mol Med 46: 3-16, 2020.

45. Huang C, Wang Y, Li X, Ren L, Zhao J, Hu Y, Zhang L, Fan G, $\mathrm{Xu} \mathrm{J}, \mathrm{Gu} \mathrm{X}$, et al: Clinical features of patients infected with 2019 novel coronavirus in Wuhan, China. Lancet 395: 497-506, 2020

46. Wang F, Nie J, Wang H, Zhao Q, Xiong Y, Deng L, Song S, Ma Z, Mo P and Zhang Y: Characteristics of peripheral lymphocyte subset alteration in COVID-19 pneumonia. J Infect Dis 221: $1762-1769,2020$

47. Tu YF, Chien CS, Yarmishyn AA, Lin YY, Luo YH, Lin YT, Lai WY, Yang DM, Chou SJ, Yang YP, et al: A Review of SARS-CoV-2 and the Ongoing Clinical Trials. Int J Mol Sci 21 21, 2020.

48. Wu C, Liu Y, Yang Y, Zhang P, Zhong W, Wang Y, Wang Q, Xu Y, Li M, Li X, et al: Analysis of therapeutic targets for SARS-CoV-2 and discovery of potential drugs by computational methods. Acta Pharm Sin B: Feb 27, 2020 (Epub ahead of print).

49. Shojaei A and Salari P: COVID-19 and off label use of drugs: An ethical viewpoint. Daru: May 8, 2020 (Epub ahead of print).

50. Senanayake SL: Drug repurposing strategies for COVID-19. Future Drug Discov: fdd-2020-0010, 2020.

51. Sanders JM, Monogue ML, Jodlowski TZ and Cutrell JB: Pharmacologic treatments for coronavirus disease 2019 (COVID-19): A Review. JAMA 323: 1824-1836, 2020

52. Haschke M, Schuster M, Poglitsch M, Loibner H, Salzberg M, Bruggisser M, Penninger J and Krähenbühl S: Pharmacokinetics and pharmacodynamics of recombinant human angiotensin-converting enzyme 2 in healthy human subjects. Clin Pharmacokinet 52: 783-792, 2013

53. Wilkins MR, Aman J, Harbaum L, Ulrich A, Wharton J and Rhodes CJ: Recent advances in pulmonary arterial hypertension. F1000Research 7: F1000 Faculty Rev-1128, 2018.
54. Khan A, Benthin C, Zeno B, Albertson TE, Boyd J, Christie JD, Hall R, Poirier G, Ronco JJ, Tidswell M, et al: A pilot clinical trial of recombinant human angiotensin-converting enzyme 2 in acute respiratory distress syndrome. Crit Care 21: 234, 2017.

55. Batlle D, Wysocki J and Satchell K: Soluble angiotensin-converting enzyme 2: A potential approach for coronavirus infection therapy? Clin Sci (Lond) 134: 543-545, 2020

56. U.S. National Library of Medicine: Recombinant Human Angiotensin-converting Enzyme 2 (rhACE2) as a Treatment for Patients With COVID-19 (APN01-COVID-19). ClinicalTrials. gov Identifier: NCT04335136. https://clinicaltrials.gov/ct2/show/ NCT04335136?term $=$ NCT04335136\&draw $=2 \&$ rank $=1$. Accessed April 6, 2020

57. Han Y and Král P: Computational design of ACE2-based peptide inhibitors of SARS-CoV-2. ACS Nano 14: 5143-5147, 2020.

58. Heinemann L, Baughman R, Boss A and Hompesch M: Pharmacokinetic and pharmacodynamic properties of a novel inhaled insulin. J Diabetes Sci Technol 11: 148-156, 2017.

59. Deng J, Wang D-X, Deng W, Li C-Y and Tong J: The effect of endogenous angiotensin II on alveolar fluid clearance in rats with acute lung injury. Can Respir J 19: 311-318, 2012

60. Hernández Prada JA, Ferreira AJ, Katovich MJ, Shenoy V, Qi Y, Santos RA, Castellano RK, Lampkins AJ, Gubala V, Ostrov DA, et al: Structure-based identification of small-molecule angiotensin-converting enzyme 2 activators as novel antihypertensive agents. Hypertension 51: 1312-1317, 2008.

61. Qi Y, Zhang J, Cole-Jeffrey CT, Shenoy V, Espejo A, Hanna M, Song C, Pepine CJ, Katovich MJ and Raizada MK: Diminazene aceturate enhances angiotensin-converting enzyme 2 activity and attenuates ischemia-induced cardiac pathophysiology. Hypertension 62: 746-752, 2013.

62. Qaradakhi T, Gadanec LK, McSweeney KR, Tacey A, Apostolopoulos V, Levinger I, Rimarova K, Egom EE, Rodrigo L, Kruzliak P, et al: The potential actions of angiotensin-converting enzyme II (ACE2) activator diminazene aceturate (DIZE) in various diseases. Clin Exp Pharmacol Physiol 47: 751-758, 2020.

63. Gurwitz D: Angiotensin receptor blockers as tentative SARS-CoV-2 therapeutics. Drug Dev Res: Mar 4, 2020 (Epub ahead of print)

64. Ishikura H, Nishimura $S$, Matsunami M, Tsujiuchi T, Ishiki $T$, Sekiguchi F, Naruse M,Nakatani T, Kamanaka Y and Kawabata A: The proteinase inhibitor camostat mesilate suppresses pancreatic pain in rodents. Life Sci 80: 1999-2004, 2007.

65. Zhou Y, Vedantham P, Lu K, Agudelo J, Carrion R Jr, Nunneley JW, Barnard D, Pöhlmann S, McKerrow JH, Renslo AR, et al: Protease inhibitors targeting coronavirus and filovirus entry. Antiviral Res 116: 76-84, 2015.

66. Kawase M, Shirato K, van der Hoek L, Taguchi $F$ and Matsuyama S: Simultaneous treatment of human bronchial epithelial cells with serine and cysteine protease inhibitors prevents severe acute respiratory syndrome coronavirus entry. J Virol 86: 6537-6545, 2012.

67. Tarnow C, Engels G, Arendt A, Schwalm F, Sediri H, Preuss A Nelson PS, Garten W, Klenk HD, Gabriel G, et al: TMPRSS2 is a host factor that is essential for pneumotropism and pathogenicity of H7N9 influenza A virus in mice. J Virol 88: 4744-4751, 2014.

68. Fuwa M, Kageyama M, Ohashi K, Sasaoka M, Sato R, Tanaka M and Tashiro K: Nafamostat and sepimostat identified as novel neuroprotective agents via NR2B N-methyl-D-aspartate receptor antagonism using a rat retinal excitotoxicity model. Sci Rep 9: 20409, 2019.

69. Yamamoto M, Matsuyama S, Li X, Takeda M, Kawaguchi Y, Inoue JI and Matsuda Z: Identification of Nafamostat as a potent inhibitor of Middle East Respiratory Syndrome Coronavirus S Protein-mediated membrane fusion using the Split-Protein-Based Cell-Cell Fusion Assay. Antimicrob Agents Chemother 60 6532-6539, 2016.

70. Wang M, Cao R, Zhang L, Yang X, Liu J, Xu M, Shi Z, Hu Z, Zhong $\mathrm{W}$ and Xiao G: Remdesivir and chloroquine effectively inhibit the recently emerged novel coronavirus $(2019-\mathrm{nCoV})$ in vitro. Cell Res 30: 269-271, 2020.

71. Lee YK, Lee HW, Choi KH and Kim BS: Ability of nafamostat mesilate to prolong filter patency during continuous renal replacement therapy in patients at high risk of bleeding: A randomized controlled study. PLoS One 9: e108737, 2014.

72. Lucas JM, Heinlein C, Kim T, Hernandez SA, Malik MS, True LD, Morrissey C, Corey E, Montgomery B, Mostaghel E, et al: The androgen-regulated protease TMPRSS2 activates a proteolytic cascade involving components of the tumor microenvironment and promotes prostate cancer metastasis. Cancer Discov 4: $1310-1325,2014$ 
73. Laporte $M$ and Naesens L: Airway proteases: An emerging drug target for influenza and other respiratory virus infections. Curr Opin Virol 24: 16-24, 2017.

74. Maggio R and Corsini GU: Repurposing the mucolytic cough suppressant and TMPRSS2 protease inhibitor bromhexine for the prevention and management of SARS-CoV-2 infection. Pharmacol Res 157: 104837, 2020.

75. Zhirnov OP, Matrosovich TY, Matrosovich MN and Klenk HD: Aprotinin, a protease inhibitor, suppresses proteolytic activation of pandemic H1N1v influenza virus. Antivir Chem Chemother 21: 169-174, 2011

76. Bojkova D, McGreig JE, McLaughlin KM, Masterson SG Widera M, Krähling V, Ciesek S, Wass MN, Michaelis M and Cinatl J Jr: SARS-CoV-2 and SARS-CoV differ in their cell tropism and drug sensitivity profiles. bioRxiv: doi: https://doi. org/10.1101/2020.04.03.024257.

77. Chen Z, Mi L, Xu J, Yu J, Wang X, Jiang J, Xing J, Shang P, Qian A, Li Y, et al: Function of HAb18G/CD147 in invasion of host cells by severe acute respiratory syndrome coronavirus. J Infect Dis 191: 755-760, 2005.

78. Watanabe A, Yoneda M, Ikeda F, Terao-Muto Y, Sato H and Kai C: CD147/EMMPRIN acts as a functional entry receptor for measles virus on epithelial cells. J Virol 84: 4183-4193, 2010.

79. Lythgoe MP and Middleton P: Ongoing Clinical Trials for the Management of the COVID-19 Pandemic. Trends Pharmacol Sci: Apr 9, 2020 (Epub ahead of print).

80. Inoue Y, Tanaka N, Tanaka Y, Inoue S, Morita K, Zhuang M Hattori $\mathrm{T}$ and Sugamura K: Clathrin-dependent entry of severe acute respiratory syndrome coronavirus into target cells expressing ACE2 with the cytoplasmic tail deleted. J Virol 81: 8722-8729, 2007.

81. Choy KT, Wong AYL, Kaewpreedee P, Sia SF, Chen D, Hui KPY, Chu DKW, Chan MCW, Cheung PP, Huang X, et al: Remdesivir, lopinavir, emetine, and homoharringtonine inhibit SARS-CoV-2 replication in vitro. Antiviral Res 178: 104786, 2020.

82. Stebbing J, Phelan A, Griffin I, Tucker C, Oechsle O, Smith D and Richardson P: COVID-19: Combining antiviral and anti-inflammatory treatments. Lancet Infect Dis 20: 400-402, 2020.

83. Conner SD and Schmid SL: Identification of an adaptor-associated kinase, AAK1, as a regulator of clathrin-mediated endocytosis J Cell Biol 156: 921-929, 2002.

84. Sorrell FJ, Szklarz M, Abdul Azeez KR, Elkins JM and Knapp S Family-wide structural analysis of human Numb-associated protein kinases. Structure 24: 401-411, 2016.

85. Eberl HC, Werner T, Reinhard FB, Lehmann S, Thomson D, Chen P, Zhang C, Rau C, Muelbaier M, Drewes G, et al: Chemical proteomics reveals target selectivity of clinical Jak inhibitors in human primary cells. Sci Rep 9: 14159, 2019.

86. Ou X, Liu Y, Lei X, Li P, Mi D, Ren L, Guo L, Guo R, Chen T, $\mathrm{Hu}$ J, et al: Characterization of spike glycoprotein of SARS-CoV-2 on virus entry and its immune cross-reactivity with SARS-CoV. Nat Commun 11: 1620, 2020.

87. Dana D and Pathak SK: A review of small molecule inhibitors and functional probes of human Cathepsin L. Molecules 25: 698, 2020.

88. Cossart P and Helenius A: Endocytosis of viruses and bacteria Cold Spring Harb Perspect Biol 6: a016972, 2014.

89. Nicola AV, McEvoy AM and Straus SE: Roles for endocytosis and low $\mathrm{pH}$ in herpes simplex virus entry into HeLa and Chinese hamster ovary cells. J Virol 77: 5324-5332, 2003.

90. Touret $\mathrm{F}$ and de Lamballerie X: Of chloroquine and COVID-19. Antiviral Res 177: 104762, 2020.

91. Yao X, Ye F, Zhang M, Cui C, Huang B, Niu P, Liu X, Zhao L, Dong E, Song C, et al: In vitro antiviral activity and projection of optimized dosing design of hydroxychloroquine for the treatment of severe acute respiratory syndrome coronavirus 2 (SARS-CoV-2). Clin Infect Dis: Mar 9, 2020 (Epub ahead of print).

92. Devaux CA, Rolain JM, Colson P and Raoult D: New insights on the antiviral effects of chloroquine against coronavirus: What to expect for COVID-19? Int J Antimicrob Agents: Mar 12, 2020 (Epub ahead of print).

93. Biot C, Daher W, Chavain N, Fandeur T, Khalife J, Dive D and De Clercq E: Design and synthesis of hydroxyferroquine derivatives with antimalarial and antiviral activities. J Med Chem 49 2845-2849, 2006.

94. de Wilde AH,Jochmans D, Posthuma CC, Zevenhoven-Dobbe JC, van Nieuwkoop S, Bestebroer TM, van den Hoogen BG, Neyts J and Snijder EJ: Screening of an FDA-approved compound library identifies four small-molecule inhibitors of Middle East respiratory syndrome coronavirus replication in cell culture. Antimicrob Agents Chemother 58: 4875-4884, 2014.
95. Vincent MJ, Bergeron E, Benjannet S, Erickson BR, Rollin PE, Ksiazek TG, Seidah NG and Nichol ST: Chloroquine is a potent inhibitor of SARS coronavirus infection and spread. Virol J 2: $69,2005$.

96. Cortegiani A, Ingoglia G, Ippolito M, Giarratano A and Einav S A systematic review on the efficacy and safety of chloroquine for the treatment of COVID-19. J Crit Care: Mar 10, 2020 (Epub ahead of print).

97. Gao J, Tian Z and Yang X: Breakthrough: Chloroquine phosphate has shown apparent efficacy in treatment of COVID-19 associated pneumonia in clinical studies. Biosci Trends 14: 72-73, 2020.

98. Guangdong Provincial Department of Science and Technology and Guangdong Provincial Health Commission Multi-center Collaborative Group of chloroquine phosphate for the treatment of New Coronavirus Pneumonia: Expert consensus on the treatment of new coronavirus pneumonia with chloroquine phosphate. Zhonghua Jie He He Hu Xi Za Zhi 43: 185-188, 2020.

99.Liu J, Cao R, Xu M, Wang X, Zhang H, Hu H, Li Y, Hu Z, Zhong W and Wang M: Hydroxychloroquine, a less toxic derivative of chloroquine, is effective in inhibiting SARS-CoV-2 infection in vitro. Cell Discov 6: 16, 2020.

100. Chen Z, Hu J, Zhang Z, Jiang S, Han S, Yan D, Zhuang R, Hu B and Zhang Z: Efficacy of hydroxychloroquine in patients with COVID-19: results of a randomized clinical trial. medRxiv: doi: https://doi.org/10.1101/2020.03.22.20040758.

101. Gautret P, Lagier JC, Parola P, Hoang VT, Meddeb L, Mailhe M, Doudier B, Courjon J, Giordanengo V, Vieira VE, et al: Hydroxychloroquine and azithromycin as a treatment of COVID-19: Results of an open-label non-randomized clinical trial. Int J Antimicrob Agents: Mar 20, 2020 (Epub ahead of print).

102. Hickley NM, Al-Maskari A and McKibbin M: Chloroquine and hydroxychloroquine toxicity. Arch Ophthalmol 129: 1506-1507, 2011.

103. Taccone FS, Gorham J and Vincent JL: Hydroxychloroquine in the management of critically ill patients with COVID-19: The need for an evidence base. Lancet Respir Med: Apr 15, 2020 (Epub ahead of print)

104. Magagnoli J, Narendran S, Pereira F, Cummings T, Hardin JW, Sutton SS and Ambati J: Outcomes of hydroxychloroquine usage in United States veterans hospitalized with Covid-19. medRxiv: doi: https://doi.org/10.1101/2020.04.16.20065920.

105. Xue X, Yu H, Yang H, Xue F, Wu Z, Shen W, Li J, Zhou Z, Ding Y, Zhao Q, et al: Structures of two coronavirus main proteases: implications for substrate binding and antiviral drug design. J Virol 82: 2515-2527, 2008

106. Hall DC Jr and Ji HF: A search for medications to treat COVID-19 via in silico molecular docking models of the SARS-CoV-2 spike glycoprotein and 3CL protease. Travel Med Infect Dis: Apr 12, 2020 (Epub ahead of print).

107.Zhang L, Lin D, Kusov Y, Nian Y, Ma Q, Wang J, von Brunn A, Leyssen P, Lanko K, Neyts J, et al: $\alpha$-Ketoamides as broad-spectrum inhibitors of coronavirus and enterovirus replication: structure-based design, synthesis, and activity assessment. J Med Chem 63: 4562-4578, 2020

108.Zhang L, Lin D, Sun X, Curth U, Drosten C, Sauerhering L, Becker S, Rox K and Hilgenfeld R: Crystal structure of SARS-CoV-2 main protease provides a basis for design of improved $\alpha$-ketoamide inhibitors. Science 368: 409-412, 2020.

109. Croxtall JD and Perry CM: Lopinavir/Ritonavir: A review of its use in the management of HIV-1 infection. Drugs 70: 1885-1915, 2010.

110. Chen F, Chan KH, Jiang Y, Kao RY, Lu HT, Fan KW, Cheng VC, Tsui WH, Hung IF and Lee TS: In vitro susceptibility of 10 clinical isolates of SARS coronavirus to selected antiviral compounds. J Clin Virol 31: 69-75, 2004.

111. Yamamoto N, Matsuyama S, Hoshino T and Yamamoto N: Nelfinavir inhibits replication of severe acute respiratory syndrome coronavirus 2 in vitro. bioRxiv: doi: https://doi. org/10.1101/2020.04.06.026476.

112. Cao B, Wang Y, Wen D, Liu W, Wang J, Fan G, Ruan L, Song B, Cai Y, Wei M, et al: A Trial of Lopinavir-Ritonavir in Adults Hospitalized with Severe Covid-19. N Engl J Med 382: 1787-1799, 2020.

113. Boopathi S, Poma AB and Kolandaivel P: Novel 2019 coronavirus structure, mechanism of action, antiviral drug promises and rule out against its treatment. J Biomol Struct Dyn: Apr 30, 2020 (Epub ahead of print). 
114. Yamamoto N, Yang R, Yoshinaka Y, Amari S, Nakano T, Cinatl J, Rabenau H, Doerr HW, Hunsmann G, Otaka A, et al: HIV protease inhibitor nelfinavir inhibits replication of SARS-associated coronavirus. Biochem Biophys Res Commun 318: 719-725, 2004.

115. Fintelman-Rodrigues N, Sacramento CQ, Lima CR, da Silva FS, Ferreira AC, Mattos M, de Freitas CS, Soares VC, da Silva Gomes Dias S, Temerozo JR, et al: Atazanavir inhibits SARS-CoV-2 replication and pro-inflammatory cytokine production. bioRxiv: doi: https://doi. org/10.1101/2020.04.04.020925.

116. Agostini ML, Andres EL, Sims AC, Graham RL, Sheahan TP, Lu X, Smith EC, Case JB, Feng JY, Jordan R, et al: Coronavirus susceptibility to the antiviral remdesivir (GS-5734) is mediated by the viral polymerase and the proofreading exoribonuclease. MBio 9: e00221-e18, 2018.

117. Gao Y, Yan L, Huang Y, Liu F, Zhao Y, Cao L, Wang T, Sun Q, Ming Z, Zhang L, et al: Structure of the RNA-dependent RNA polymerase from COVID-19 virus. Science: Apr 10, 2020 (Epub ahead of print).

118. Smith EC: The not-so-infinite malleability of RNA viruses: Viral and cellular determinants of RNA virus mutation rates. PLoS Pathog 13: e1006254-e1006254, 2017.

119. Smith EC, Blanc H, Surdel MC, Vignuzzi M and Denison MR: Coronaviruses lacking exoribonuclease activity are susceptible to lethal mutagenesis: Evidence for proofreading and potential therapeutics. PLoS Pathog 9: e1003565-e1003565, 2013.

120. Becares M, Pascual-Iglesias A, Nogales A, Sola I, Enjuanes L and Zuñiga S: Mutagenesis of Coronavirus nsp14 reveals its potential role in modulation of the innate immune response. J Virol 90: 5399-5414, 2016.

121. De Clercq E and Li G: DC approved antiviral drugs over the past 50 years. Clin Microbiol Rev 29: 695-747, 2016.

122. Elfiky AA: Ribavirin, Remdesivir, Sofosbuvir, Galidesivir, and Tenofovir against SARS-CoV-2 RNA dependent RNA polymerase (RdRp): A molecular docking study. Life Sci 253: $117592,2020$.

123. Amirian ES and Levy JK: Current knowledge about the antivirals remdesivir (GS-5734) and GS-441524 as therapeutic options for coronaviruses. One Health 9: 100128, 2020

124. US Food and Drug Administration (FDA): Recommendations for InvestigationalCOVID-19ConvalescentPlasma.https://www.fda. gov/vaccines-blood-biologics/investigational-new-drug-ind-ordevice-exemption-ide-process-cber/recommendations-investigational-covid-19-convalescent-plasma. Accessed May 1, 2020.

125. Mulangu S, Dodd LE, Davey RT Jr, Tshiani Mbaya O, Proschan M, Mukadi D, Lusakibanza Manzo M, Nzolo D, Tshomba Oloma A, Ibanda A, et al; PALM Writing Group; PALM Consortium Study Team: A Randomized, Controlled Trial of Ebola Virus Disease Therapeutics. N Engl J Med 381: 2293-2303, 2019.

126. Holshue ML, DeBolt C, Lindquist S, Lofy KH, Wiesman J Bruce H, Spitters C, Ericson K, Wilkerson S, Tural A, et al Washington State 2019-nCoV Case Investigation Team: First Case of 2019 Novel Coronavirus in the United States. N Engl J Med 382: 929-936, 2020.

127. COVID-19 Investigation Team: Clinical and virologic characteristics of the first 12 patients with coronavirus disease 2019 (COVID-19) in the United States. Nat Med: Apr 23, 2020 (Epub ahead of print).

128. Wang Y, Zhang D, Du G, Du R, Zhao J, Jin Y, Fu S, Gao L, Cheng Z, Lu Q, et al: Remdesivir in adults with severe COVID-19: A randomised, double-blind, placebo-controlled, multicentre trial. Lancet 395: P1569-P1578, 2020

129. Furuta Y, Takahashi K, Kuno-Maekawa M, Sangawa H, Uehara S Kozaki K, Nomura N, Egawa H and Shiraki K: Mechanism of action of T-705 against influenza virus. Antimicrob Agents Chemother 49: 981-986, 2005

130. Furuta Y, Gowen BB, Takahashi K, Shiraki K, Smee DF and Barnard DL: Favipiravir (T-705), a novel viral RNA polymerase inhibitor. Antiviral Res 100: 446-454, 2013.

131.Jordan PC, Stevens SK and Deval J: Nucleosides for the treatment of respiratory RNA virus infections. Antivir Chem Chemother 26: 2040206618764483, 2018.

132. Madelain V, Nguyen THT, Olivo A, de Lamballerie X, Guedj J, Taburet A-M and Mentré F: Ebola virus infection: Review of the pharmacokinetic and pharmacodynamic properties of drugs considered for testing in human efficacy trials. Clin Pharmacokinet 55: 907-923, 2016.
133. Nagata T, Lefor AK, Hasegawa M and Ishii M: Favipiravir: A new medication for the Ebola virus disease pandemic. Disaster Med Public Health Prep 9: 79-81, 2015.

134.Cai Q, Yang M, Liu D, Chen J, Shu D, Xia J, Liao X, Gu Y, Cai Q, Yang Y, et al: Experimental Treatment with Favipiravir for COVID-19: An Open-Label Control Study. Engineering (Beijing): Mar 18, 2020 (Epub ahead of print).

135. Warren TK, Wells J, Panchal RG, Stuthman KS, Garza NL, Van Tongeren SA, Dong L, Retterer CJ, Eaton BP, Pegoraro G, et al: Protection against filovirus diseases by a novel broad-spectrum nucleoside analogue BCX4430. Nature 508: 402-405, 2014

136. Taylor R, Kotian P, Warren T, Panchal R, Bavari S, Julander J, Dobo S, Rose A, El-Kattan Y, Taubenheim B, et al: BCX4430 - A broad-spectrum antiviral adenosine nucleoside analog under development for the treatment of Ebola virus disease. J Infect Public Health 9: 220-226, 2016.

137. De Clercq E: New nucleoside analogues for the treatment of hemorrhagic fever virus infections. Chem Asian J 14: 3962-3968, 2019.

138. Sheahan TP, Sims AC, Zhou S, Graham RL, Pruijssers AJ, Agostini ML, Leist SR, Schäfer A, Dinnon KH III, Stevens LJ, et al: An orally bioavailable broad-spectrum antiviral inhibits SARS-CoV-2 in human airway epithelial cell cultures and multiple coronaviruses in mice. Sci Transl Med 12: eabb5883, 2020.

139. Agostini ML, Pruijssers AJ, Chappell JD, Gribble J, Lu X, Andres EL, Bluemling GR, Lockwood MA, Sheahan TP, Sims AC, etal:Small-moleculeantiviral $\beta$-d-N4-Hydroxycytidine inhibits a proofreading-intact Coronavirus with a high genetic barrier to resistance. J Virol 93: e01348-e19, 2019.

140. Stockman LJ, Bellamy R and Garner P: SARS: Systematic review of treatment effects. PLoS Med 3: e343-e343, 2006.

141. Moens U and Macdonald A: Effect of the large and small T-antigens of human polyomaviruses on signaling pathways. Int J Mol Sci 20: 20, 2019.

142. Gassen NC, Niemeyer D, Muth D, Corman VM, Martinelli S, Gassen A, Hafner K, Papies J, Mösbauer K, Zellner A, et al: SKP2 attenuates autophagy through Beclin1-ubiquitination and its inhibition reduces MERS-Coronavirus infection. Nat Commun 10: 5770, 2019.

143. Gassen NC,Papies J,Bajaj T, DethloffF,Emanuel J, Weckmann K, Heinz DE, Heinemann N, Lennarz M, Richter A, et al: Analysis of SARS-CoV-2-controlled autophagy reveals spermidine, MK-2206, and niclosamide as putative antiviral therapeutics. bioRxiv: doi: https://doi.org/10.1101/2020.04.15.997254.

144. Mizutani T, Fukushi S, Saijo M, Kurane I and Morikawa S: Importance of Akt signaling pathway for apoptosis in SARS-CoV-infected Vero E6 cells. Virology 327: 169-174, 2004.

145. Nitulescu GM, Margina D, Juzenas P, Peng Q, Olaru OT, Saloustros E, Fenga C, Spandidos DA, Libra $M$ and Tsatsakis AM: Akt inhibitors in cancer treatment: The long journey from drug discovery to clinical use (Review). Int J Oncol 48: 869-885, 2016

146. Denisova OV, Söderholm S, Virtanen S, Von Schantz C, Bychkov D, Vashchinkina E, Desloovere J, Tynell J, Ikonen N, Theisen LL, et al: Akt inhibitor MK2206 prevents influenza pH1N1 virus infection in vitro. Antimicrob Agents Chemother 58: 3689-3696, 2014

147. Kindrachuk J, Ork B, Hart BJ, Mazur S, Holbrook MR, Frieman MB, Traynor D, Johnson RF, Dyall J, Kuhn JH, et al: Antiviral potential of ERK/MAPK and PI3K/AKT/mTOR signaling modulation for Middle East respiratory syndrome coronavirus infection as identified by temporal kinome analysis. Antimicrob Agents Chemother 59: 1088-1099, 2015.

148. De Santi M, Baldelli G, Diotallevi A, Galluzzi L, Schiavano GF and Brandi G: Metformin prevents cell tumorigenesis through autophagy-related cell death. Sci Rep 9: 66, 2019.

149. Lehrer S: Inhaled biguanides and mTOR inhibition for influenza and coronavirus (Review). World Acad Sci J 2: 1, 2020.

150. Chen W, Mook RA Jr, Premont RT and Wang J: Niclosamide: Beyond an antihelminthic drug. Cell Signal 41: 89-96, 2018.

151. Wu CJ, Jan JT, Chen CM, Hsieh HP, Hwang DR, Liu HW, Liu CY, Huang HW, Chen SC, Hong CF, et al: Inhibition of severe acute respiratory syndrome coronavirus replication by niclosamide. Antimicrob Agents Chemother 48: 2693-2696, 2004

152. Wen CC, Kuo YH, Jan JT, Liang PH, Wang SY, Liu HG, Lee CK, Chang ST, Kuo CJ, Lee SS, et al: Specific plant terpenoids and lignoids possess potent antiviral activities against severe acute respiratory syndrome coronavirus. J Med Chem 50: 4087-4095, 2007. 
153. Jurgeit A, McDowell R, Moese S, Meldrum E, Schwendener R and Greber UF: Niclosamide is a proton carrier and targets acidic endosomes with broad antiviral effects. PLoS Pathog 8 : e1002976-e1002976, 2012

154. Schweizer MT, Haugk K, McKiernan JS, Gulati R, Cheng HH, Maes JL, Dumpit RF, Nelson PS, Montgomery B, McCune JS, et al: A phase I study of niclosamide in combination with enzalutamide in men with castration-resistant prostate cancer. PLoS One 13: e0198389, 2018.

155.Pizzorno A, Terrier O, Nicolas de Lamballerie C, Julien T, Padey B, Traversier A, Roche M, Hamelin ME, Rhéaume C, Croze $\mathrm{S}$, et al: Repurposing of drugs as novel influenza inhibitors from clinical gene expression infection signatures. Front Immunol 10: 60, 2019.

156. Rossignol J-F: Nitazoxanide, a new drug candidate for the treatment of Middle East respiratory syndrome coronavirus. J Infect Public Health 9: 227-230, 2016.

157. Shou J, Wang M, Cheng X, Wang X, Zhang L, Liu Y, Fei C, Wang C, Gu F, Xue F, et al: Tizoxanide induces autophagy by inhibiting PI3K/Akt/mTOR pathway in RAW264.7 macrophage cells. Arch Pharm Res 43: 257-270, 2020.

158.Blaising J, Polyak SJ and Pécheur E-I: Arbidol as a broad-spectrum antiviral: An update. Antiviral Res 107: 84-94, 2014.

159. Haviernik J, Štefánik M, Fojtíková M, Kali S, Tordo N, Rudolf I, Hubálek Z, Eyer L and Ruzek D: Arbidol (Umifenovir): A broad-spectrum antiviral drug that inhibits medically important arthropod-borne flaviviruses. Viruses 10: 184, 2018.

160.Zhu Z, Lu Z, Xu T, Chen C, Yang G, Zha T, Lu J and Xue Y: Arbidol monotherapy is superior to lopinavir/ritonavir in treating COVID-19. J Infect: Apr 10, 2020 (Epub ahead of print).

161. Deng L, Li C, Zeng Q, Liu X, Li X, Zhang H, Hong Z and Xia J: Arbidol combined with LPV/r versus LPV/r alone against Corona Virus Disease 2019: A retrospective cohort study. J Infect: Mar 11, 2020 (Epub ahead of print).

162.Lian N, Xie H, Lin S, Huang J, Zhao J and Lin Q: Umifenovir treatment is not associated with improved outcomes in patients with coronavirus disease 2019: A retrospective study. Clin Microbiol Infect: Apr 25, 2020 (Epub ahead of print)

163. Wang X, Cao R, Zhang H, Liu J, Xu M, Hu H, Li Y, Zhao L, $\mathrm{Li}$ W, Sun $\mathrm{X}$, et al: The anti-influenza virus drug, arbidol is an efficient inhibitor of SARS-CoV-2 in vitro. Cell Discov 6: 28 , 2020.

164. Crump A: Ivermectin: Enigmatic multifaceted 'wonder' drug continues to surprise and exceed expectations. J Antibiot (Tokyo) 70: 495-505, 2017

165. Caly L, Druce JD, Catton MG, Jans DA and Wagstaff KM: The FDA-approved drug ivermectin inhibits the replication of SARS-CoV-2 in vitro. Antiviral Res 178: 104787, 2020.

166. Yang SNY, Atkinson SC, Wang C, Lee A, Bogoyevitch MA, Borg NA and Jans DA: The broad spectrum antiviral ivermectin targets the host nuclear transport importin $\alpha / \beta 1$ heterodimer. Antiviral Res 177: 104760, 2020.

167. Juarez M, Schcolnik-Cabrera A and Dueñas-Gonzalez A: The multitargeted drug ivermectin: From an antiparasitic agent to a repositioned cancer drug. Am J Cancer Res 8: 317-331, 2018

168. Shen L, Niu J, Wang C, Huang B, Wang W, Zhu N, Deng Y, Wang H, Ye F, Cen S, et al: High-throughput screening and identification of potent broad-spectrum inhibitors of Coronaviruses. J Virol 93: e00023-e19, 2019.

169. Dong HJ, Wang ZH, Meng W, Li CC, Hu YX, Zhou L and Wang XJ: The natural compound Homoharringtonine presents broad antiviral activity in Vitro and in Vivo. Viruses 10: 601, 2018

170.Gordon DE, Jang GM, Bouhaddou M, Xu J, Obernier K, White KM, O'Meara MJ, Rezelj VV, Guo JZ, Swaney DL, et al: A SARS-CoV-2 protein interaction map reveals targets for drug repurposing. Nature: Apr 30, 2020 (Epub ahead of print).

171. D'Elia RV, Harrison K, Oyston PC, Lukaszewski RA and Clark GC: Targeting the 'cytokine storm' for therapeutic benefit. Clin Vaccine Immunol 20: 319-327, 2013.

172. Tay MZ, Poh CM, Rénia L, MacAry PA and Ng LFP: The trinity of COVID-19: Immunity, inflammation and intervention. Nat Rev Immunol: Apr 28, 2020 (Epub ahead of print).

173. Petrakis D, Margină D, Tsarouhas K, Tekos F, Stan M, Nikitovic D, Kouretas D, Spandidos DA and Tsatsakis A: Obesity a risk factor for increased COVID-19 prevalence, severity and lethality (Review). Mol Med Rep 22: 9-19, 2020.

174. Velazquez-Salinas L, Verdugo-Rodriguez A, Rodriguez LL and Borca MV: The role of interleukin 6 during viral infections. Front Microbiol 10: 1057, 2019.
175. Mehta P, McAuley DF, Brown M, Sanchez E, Tattersall RS and Manson JJ; HLH Across Speciality Collaboration, UK: COVID-19: Consider cytokine storm syndromes and immunosuppression. Lancet 395: 1033-1034, 2020.

176. Betts BC, St Angelo ET, Kennedy $M$ and Young JW: Anti-IL6-receptor-alpha (tocilizumab) does not inhibit human monocyte-derived dendritic cell maturation or alloreactive T-cell responses. Blood 118: 5340-5343, 2011.

177. Reichert JM: Which are the antibodies to watch in 2013 ? MAbs 5: 1-4, 2013

178. Chinese Clinical Trial Registry (ChiCTR): A clinical study for the efficacy and safety of Adalimumab Injection in the treatment of patients with severe novel coronavirus pneumonia (COVID-19). Registration number: ChiCTR2000030089. http:// www.chictr.org.cn/showprojen.aspx?proj=49889. Accessed February 22, 2020

179. Kamimura D, Ishihara $\mathrm{K}$ and Hirano T: IL-6 signal transduction and its physiological roles: The signal orchestration model. Rev Physiol Biochem Pharmacol 149: 1-38, 2003.

180. Kaur S, Bansal Y, Kumar R and Bansal G: A panoramic review of IL-6: Structure, pathophysiological roles and inhibitors. Bioorganic Med Chem 28: 115327, 2020.

181. Rose-John S: IL-6 trans-signaling via the soluble IL-6 receptor: Importance for the pro-inflammatory activities of IL-6. Int J Biol Sci 8: 1237-1247, 2012.

182. Chen N, Zhou M, Dong X, Qu J, Gong F, Han Y, Qiu Y, Wang J, Liu Y, Wei Y, et al: Epidemiological and clinical characteristics of 99 cases of 2019 novel coronavirus pneumonia in Wuhan, China: A descriptive study. Lancet 395: 507-513, 2020.

183. Qin C, Zhou L, Hu Z, Zhang S, Yang S, Tao Y, Xie C, Ma K, Shang K, Wang W and Tian DS: Dysregulation of immune response in patients with COVID-19 in Wuhan, China. Clin Infect Dis: Mar 12: 2020 (Epub ahead of print).

184.Zhou F, Yu T, Du R, Fan G, Liu Y, Liu Z, Xiang J, Wang Y, Song B, Gu X, et al: Clinical course and risk factors for mortality of adult inpatients with COVID-19 in Wuhan, China: A retrospective cohort study. Lancet 395: 1054-1062, 2020.

185. Jamilloux Y, Henry T, Belot A, Viel S, Fauter M, El Jammal T, Walzer T, François B and Sève P: Should we stimulate or suppress immune responses in COVID-19? Cytokine and anti-cytokine interventions. Autoimmun Rev: May 4, 2020 (Epub ahead of print).

186. Srirangan S and Choy EH: The role of interleukin 6 in the pathophysiology of rheumatoid arthritis. Ther Adv Musculoskele Dis 2: 247-256, 2010.

187. Alzghari SK and Acuña VS: Supportive treatment with Tocilizumab for COVID-19: A systematic review. J Clin Virol 127: 104380, 2020.

188. Sciascia S, Aprà $\mathrm{F}$, Baffa $\mathrm{A}$, Baldovino $\mathrm{S}$, Boaro $\mathrm{D}$, Boero $\mathrm{R}$, Bonora S, Calcagno A, Cecchi I, Cinnirella G, et al: Pilot prospective open, single-arm multicentre study on off-label use of tocilizumab in patients with severe COVID-19. Clin Exp Rheumatol: May 1, 2020 (Epub ahead of print).

189. Bae SC and Lee YH: Comparison of the efficacy and tolerability of tocilizumab, sarilumab, and sirukumab in patients with active rheumatoid arthritis: A Bayesian network meta-analysis of randomized controlled trials. Clin Rheumatol 37: 1471-1479, 2018.

190. Russell B, Moss C, George G, Santaolalla A, Cope A, Papa S and Van Hemelrijck M: Associations between immune-suppressive and stimulating drugs and novel COVID-19 - a systematic review of current evidence. Ecancermedicalscience 14: 1022, 2020.

191. Dinarello CA: The IL-1 family and inflammatory diseases. Clin Exp Rheumatol 20 (Suppl 27): S1-S13, 2002

192. Sichelstiel A, Yadava K, Trompette A, Salami O, Iwakura Y, Nicod LP and Marsland BJ: Targeting IL-1 $\beta$ and IL-17A driven inflammation during influenza-induced exacerbations of chronic lung inflammation. PLoS One 9: e98440, 2014.

193. Feldmann M, Maini RN, Woody JN, Holgate ST, Winter G, Rowland M, Richards D and Hussell T: Trials of anti-tumour necrosis factor therapy for COVID-19 are urgently needed. Lancet 395: 1407-1409, 2020.

194. Farsalinos K, Niaura R, Le Houezec J, Barbouni A, Tsatsakis A, Kouretas D, Vantarakis A and Poulas K: Editorial: Nicotine and SARS-CoV-2: COVID-19 may be a disease of the nicotinic cholinergic system. Toxicol Rep: Apr 30, 2020 (Epub ahead of print)

195. Berlin I, Thomas D, Le Faou AL and Cornuz J: COVID-19 and smoking. Nicotine Tob Res: Apr 3, 2020 (Epub ahead of print). 
196. Arimori Y,Nakamura R, Yamada H, Shibata K, Maeda N, Kase T and Yoshikai Y: Type I interferon limits influenza virus-induced acute lung injury by regulation of excessive inflammation in mice. Antiviral Res 99: 230-237, 2013.

197.Lokugamage KG, Hage A, Schindewolf C, Rajsbaum R and Menachery VD: SARS-CoV-2 sensitive to type I interferon pretreatment. bioRxiv: doi: https://doi.org/10.1101/ 2020.03.07.982264.

198. Mantlo E, Bukreyeva N, Maruyama J, Paessler S and Huang C: Antiviral activities of type I interferons to SARS-CoV-2 infection. Antiviral Res 179: 104811, 2020.

199. Deftereos S, Giannopoulos G, Vrachatis DA, Siasos G, Giotaki SG, Cleman M, Dangas G and Stefanadis C: Colchicine as a potent anti-inflammatory treatment in COVID-19: can we teach an old dog new tricks. Eur Hear J Cardiovasc Pharmacother: Apr 27, 2020 (Epub ahead of print).

200. Hemilä H: Vitamin C and Infections. Nutrients 9: 339, 2017.

201. Cheng RZ: Can early and high intravenous dose of vitamin C prevent and treat coronavirus disease 2019 (COVID-19)? Med drug Discov 5: 100028, 2020

202. Marik PE, Kory P and Varon J: Does vitamin D status impact mortality from SARS-CoV-2 infection? Med drug Discov: Apr 29, 2020 (Epub ahead of print).

203. Skalny AV, Rink L, Ajsuvakova OP, Aschner M, Gritsenko VA, Alekseenko SI, Svistunov AA, Petrakis D, Spandidos DA, Aaseth J, et al: Zinc and respiratory tract infections: Perspectives for COVID 19 (Review). Int J Mol Med 46: 17-26, 2020.

204. Jayawardena R, Sooriyaarachchi P, Chourdakis M, Jeewandara C and Ranasinghe P: Enhancing immunity in viral infections, with special emphasis on COVID-19: A review. Diabetes Metab Syndr 14: 367-382, 2020.

205.Langsted A and Nordestgaard BG: Antisense oligonucleotides targeting lipoprotein(a). Curr Atheroscler Rep 21: 30, 2019.

206.Li Q: Nusinersen as a therapeutic agent for spinal muscular atrophy. Yonsei Med J 61: 273-283, 2020.

207.Kim J, Hu C, Moufawad El Achkar C, Black LE, Douville J, Larson A, Pendergast MK, Goldkind SF, Lee EA, Kuniholm A, et al: Patient-customized oligonucleotide therapy for a rare genetic disease. N Engl J Med 381: 1644-1652, 2019.

208. Moschos SA, Usher L and Lindsay MA: Clinical potential of oligonucleotide-based therapeutics in the respiratory system. Pharmacol Ther 169: 83-103, 2017.

209. Ng B, Cash-Mason T, Wang Y, Seitzer J, Burchard J, Brown D, Dudkin V, Davide J, Jadhav V, Sepp-Lorenzino L, et al: Intratracheal administration of siRNA triggers mRNA silencing in the lung to modulate $\mathrm{T}$ cell immune response and lung inflammation. Mol Ther Nucleic Acids 16: 194-205, 2019.
210. Le ATH, Krylova SM, Kanoatov M, Desai S and Krylov SN: Ideal-filter capillary electrophoresis (IFCE) facilitates the one-step selection of aptamers. Angew Chem Int Ed Engl 58 2739-2743, 2019.

211. Yufa R, Krylova SM, Bruce C, Bagg EA, Schofield CJ and Krylov SN: Emulsion PCR significantly improves nonequilibrium capillary electrophoresis of equilibrium mixtures-based aptamer selection: Allowing for efficient and rapid selection of aptamer to unmodified ABH2 protein. Anal Chem 87: 1411-1419, 2015.

212. Abbott TR, Dhamdhere G, Liu Y, Lin X, Goudy L, Zeng L, Chemparathy A, Chmura S, Heaton NS, Debs R, et al: Development of CRISPR as a prophylactic strategy to combat novel coronavirus and influenza. bioRxiv: doi: https://doi. org/10.1101/2020.03.13.991307.

213. Schopman NCT, ter Brake O and Berkhout B: Anticipating and blocking HIV-1 escape by second generation antiviral shRNAs. Retrovirology 7: 52, 2010.

214. Duncan GA, Kim N, Colon-Cortes Y, Rodriguez J, Mazur M, Birket SE, Rowe SM, West NE, Livraghi-Butrico A, Boucher RC, et al: An Adeno-Associated Viral Vector Capable of Penetrating the Mucus Barrier to Inhaled Gene Therapy. Mol Ther Methods Clin Dev 9: 296-304, 2018.

215. Kurosaki F, Uchibori R, Mato N, Sehara Y, Saga Y, Urabe M, Mizukami H, Sugiyama Y and Kume A: Optimization of adeno-associated virus vector-mediated gene transfer to the respiratory tract. Gene Ther 24: 290-297, 2017.

216. Steines B, Dickey DD, Bergen J, Excoffon KJ, Weinstein JR, Li X, Yan Z, Abou Alaiwa MH, Shah VS, Bouzek DC, et al: CFTR gene transfer with AAV improves early cystic fibrosis pig phenotypes. JCI Insight 1: e88728, 2016.

217. Suhy DA, Kao SC, Mao T, Whiteley L, Denise H, Souberbielle B, Burdick AD, Hayes K, Wright JF, Lavender $\mathrm{H}$, et al: Safe, long-term hepatic expression of anti-HCV shRNA in a nonhuman primate model. Mol Ther 20: 1737-1749, 2012.

218. Denise H, Moschos SA, Sidders B, Burden F, Perkins H, Carter N, Stroud T, Kennedy M, Fancy SA, Lapthorn C, et al: Deep sequencing insights in therapeutic shRNA processing and siRNA target cleavage precision. Mol Ther Nucleic Acids 3: $\mathrm{e} 145,2014$

This work is licensed under a Creative Commons Attribution-NonCommercial-NoDerivatives 4.0 International (CC BY-NC-ND 4.0) License. 